\title{
Assessment of the reduction methods used to develop chemical schemes: building of a new chemical scheme for VOC oxidation suited to three-dimensional multiscale $\mathrm{HO}_{\mathrm{x}}-\mathrm{NO}_{\mathrm{x}}-\mathrm{VOC}$ chemistry simulations
}

\author{
S. Szopa ${ }^{1, *}$, B. Aumont ${ }^{1}$, and S. Madronich ${ }^{2}$ \\ ${ }^{1}$ Laboratoire Interuniversitaire des Systèmes Atmosphériques UMR CNRS 7583, Université Paris 7 et Paris 12, 94010 Créteil \\ Cedex, France \\ ${ }^{2}$ National Center for Atmospheric Research Atmospheric Chemistry Division, P.O. Box 3000, Boulder, Colorado 80307, USA \\ * now at: Laboratoire des Sciences du Climat et de l'Environnement UMR CNRS/CEA 1572, L'Orme des Merisiers-bat.701, \\ 91191 Gif-sur-Yvette, France
}

Received: 22 November 2004 - Published in Atmos. Chem. Phys. Discuss.: 11 February 2005

Revised: 27 May 2005 - Accepted: 5 September 2005 - Published: 22 September 2005

\begin{abstract}
The objective of this work was to develop and assess an automatic procedure to generate reduced chemical schemes for the atmospheric photooxidation of volatile organic carbon (VOC) compounds. The procedure is based on (i) the development of a tool for writing the fully explicit schemes for VOC oxidation (see companion paper Aumont et al., 2005), (ii) the application of several commonly used reduction methods to the fully explicit scheme, and (iii) the assessment of resulting errors based on direct comparison between the reduced and full schemes.

The reference scheme included seventy emitted VOCs chosen to be representative of both anthropogenic and biogenic emissions, and their atmospheric degradation chemistry required more than two million reactions among 350000 species. Three methods were applied to reduce the size of the reference chemical scheme: (i) use of operators, based on the redundancy of the reaction sequences involved in the VOC oxidation, (ii) grouping of primary species having similar reactivities into surrogate species and (iii) grouping of some secondary products into surrogate species. The number of species in the final reduced scheme is 147, this being small enough for practical inclusion in current threedimensional models. Comparisons between the fully explicit and reduced schemes, carried out with a box model for several typical tropospheric conditions, showed that the reduced chemical scheme accurately predicts ozone concentrations and some other aspects of oxidant chemistry for both polluted and clean tropospheric conditions.
\end{abstract}

Correspondence to: S. Szopa

(sophie.szopa@cea.fr)

\section{Introduction}

The atmospheric oxidation of volatile organic compounds (VOCs) modifies the concentrations of key trace species (e.g. $\mathrm{CH}_{4}, \mathrm{CO}, \mathrm{O}_{3}$ and $\mathrm{OH}$ ) and has impacts throughout the atmosphere. At urban and regional scales, VOC oxidation drives the production of high ozone concentrations close to anthropogenic activities. Globally, the reactivity of the CO$\mathrm{NO}_{\mathrm{x}}$-VOC system controls the abundance of ozone and $\mathrm{OH}$ and plays direct and indirect roles in radiative forcing and therefore climate.

Recent studies have shown the interactions of chemistry occurring at different scales. Variations of the background ozone concentrations can significantly impact the ozone values observed at regional scale (Fiore et al., 2002; Li et al., 2002; Längmann and Bauer, 2002). Furthermore, reactive species (esp. radicals and $\mathrm{NO}_{\mathrm{x}}$ ) can form reservoir species near their sources, then be redistributed over large geographic scales by convective and advective transport. Alkyl nitrates and peroxyacetyl nitrates (PANs) may be particularly effective in supplying $\mathrm{NO}_{\mathrm{x}}$ to the remote troposphere, with consequences for the net production of $\mathrm{O}_{3}$ on hemispheric or even global scales (Moxim et al., 1996). Similarly, hydroperoxydes, ketones or aldehydes could be a significant source of radicals in the free troposphere (Wennberg et al., 1998; Müller and Brasseur, 1999; Prather and Jacob, 1997).

The chemical schemes used in three-dimensional chemistry-transport models (3-D CTMs) attempt to represent the $\mathrm{HO}_{\mathrm{x}} / \mathrm{NO}_{\mathrm{x}} / \mathrm{VOC}$ chemistry both locally where high concentrations of precursors VOC and $\mathrm{NO}_{\mathrm{x}}$ may exist, and far from sources where $\mathrm{NO}_{\mathrm{x}}$ concentrations are typically

(C) 2005 Author(s). This work is licensed under a Creative Commons License. 
very low. Chemical schemes must then be suited to these different chemical regimes, and must represent the formation of, and release from, reservoir species that connect these scales.

The atmospheric chemistry of VOCs involves many hundreds of initially emitted anthropogenic or natural compounds, as well as many thousands (or more) of potentially important intermediate partly oxidized species. Representation of the fully explicit VOC chemistry in chemistry transport models (CTMs) is not currently practical due to limited computer resources, so that reduced chemical schemes must be employed that contain typically only a few hundred species, e.g. 33 species for the Carbon Bond Mechanism CBM IV (Gery et al., 1989), 64 species for RACM (Stockwell et al., 1997), and 62 species for SAPRC99 (Carter, 2000). The methods for developing these schemes have included, for example, use of surrogates or lumped species to represent a family of compounds, and truncation of some peroxy radicals reactions. The accuracy of some reduction methods may depend on the particular case under consideration, in particular the chemical regime characterizing the relative importance of the different reactions involved during VOC oxidation. Consequently, the reduction of fully explicit VOC chemistry to a smaller mechanism often limits the validity of the smaller mechanism to a specific chemical regime, e.g., highly polluted, or pristine remote, but not both.

The objective of this work was to develop and assess an automatic procedure to generate reduced chemical schemes for the atmospheric photooxidation of VOCs under various chemical regimes, from $\mathrm{NO}_{\mathrm{x}}$ limited to $\mathrm{NO}_{\mathrm{x}}$ saturated regimes. The study focuses on the $\mathrm{O}_{\mathrm{x}} / \mathrm{NO}_{\mathrm{x}} / \mathrm{HO}_{\mathrm{x}}$ chemistry and the reduction of the VOC oxidation schemes for that particular system. Attention was given to including the chemistry of secondary organics to the extent that it influences the $\mathrm{HO}_{\mathrm{x}}, \mathrm{NO}_{\mathrm{x}}$, and $\mathrm{O}_{\mathrm{x}}$ cycles. However, other aspects of organic photooxidation, such as the specific identity of compounds that could contribute to secondary organic aerosols formation, or to cloud chemistry, are not emphasized here.

A novel aspect of this work is the use of a highly detailed explicit reference scheme, developed by an automatic chemical generator code (described in a companion paper - Aumont et al., 2005), both as the initial scheme to which the reductions are applied, and as a benchmark for evaluating the accuracy of the reductions. The reduction methods were also automated, allowing fast updates of the schemes, modifications of reduction hypothesis, and "tagging" of some specific reactions to identify and quantify individual chemical processes.

This paper first describes briefly the reference chemical scheme (Sect. 2) and the various scenarios used to compare explicit and reduced schemes (Sect. 3). Secondly, the automatic procedures used to reduce the number of species and reactions in the chemical schemes are described (Sect. 4), and the biases induced by the reductions are assessed (Sects. 5 and 6). The final reduced scheme, consisting of 472 reactions among 147 species, is given in Appendix A (see supplemental material: http://www.atmos-chem-phys. org/acp/5/2519/acp-5-2519-sp.zip).

\section{The reference scheme}

As described in the companion paper (Aumont et al., 2005), the generator is a computer program that calculates and writes the fully explicit atmospheric degradation mechanism and associated kinetics for an initially specified organic compound, down to the ultimate products $\mathrm{CO}_{2}$ and $\mathrm{H}_{2} \mathrm{O}$. Reaction pathways (the products) and kinetic data are taken from laboratory measurements when available, or otherwise are computed from structure-activity relations (SARs) derived by analogy with known reactions, based on data published before 2003 as described by Laval-Szopa (2003). An important advantage of the generator method is that as new laboratory data become available, the generator code is easily updated and a revised mechanism, fully consistent with the new information, is re-generated.

The inorganic chemistry and the chemistry of one-carbon species are relatively well known and do not require new estimation of products or rate constant. This chemistry is added manually to the schemes from the generator, and is taken from the SAPRC99 mechanism updated with new data where available (Sander et al., 2000; Atkinson et al., 1999).

The reference scheme cannot include the oxidation scheme for the whole set of VOC that are emitted into the atmosphere (the size of such schemes would be unmanageable). A subset of primary species, representative of both anthropogenic and biogenic emissions must thus be first selected. This subset must be sufficiently large in order that the conclusions ultimately reached can be extended and generalized to other primary compounds not specifically considered here. The primary anthropogenic species retained here are those selected in the EUROTRAC-2 protocol for intercomparison of multiphase tropospheric chemical schemes (Poppe et al., 2001). The VOC emission partitioning in this protocol is based upon the inventory developed by Derwent and Jenkin (1991). Modifications were made to keep only species containing less than ten carbon atoms. The emissions of longer carbon chain species were added to the emissions of species having the closest structure (i.e., n-nonane for n-alkanes having ten or more carbon atoms, and methyloctanes for methyl-nonanes). To maintain carbon conservation, the emissions of species having $m$ carbons $(m \geq 10)$ was multiplied by $m / 9$. In total, emissions of 64 anthropogenic emitted VOC were considered (Table 1), plus biogenic emission of isoprene, $\alpha$-pinene and limonene. The reference chemical scheme was then built using the generator for this set of primary VOCs.

The current version of the automatic generator does not allow the treatment of cyclic species (Aumont et al., 2005), due to complications in developing a general method for their 
Table 1. Anthropogenic VOC speciation at emission used in the CMD-EUROTRAC-2 protocol (Poppe et al., 2001).

\begin{tabular}{|c|c|c|c|}
\hline $\begin{array}{l}\text { Species in EUROTRAC } \\
\text { inventory }\end{array}$ & $\begin{array}{l}\text { Percentage of total } \\
\text { emitted carbon }\end{array}$ & $\begin{array}{l}\text { Species in the EUROTRAC } \\
\text { inventory }\end{array}$ & $\begin{array}{l}\text { Percentage of total } \\
\text { emitted carbon }\end{array}$ \\
\hline Alkanes & 42 & Aromatics & 30.3 \\
\hline ethane & 1.63 & benzene & 2.46 \\
\hline propane & 0.4 & toluene & 10.43 \\
\hline n-butane & 7.64 & o-xylene & 2.41 \\
\hline i-butane & 4.15 & m-xylene & 3.12 \\
\hline n-pentane & 2.87 & p-xylene & 3.12 \\
\hline i-pentane & 4.44 & ethylbenzene & 1.98 \\
\hline n-hexane & 1.97 & n-propylbenzene & 0.46 \\
\hline 2-methylpentane & 2.23 & i-propylbenzene & 0.24 \\
\hline 3-methylpentane & 1.57 & 1,2,3-trimethylbenzene & 0.55 \\
\hline 2,2-dimethylbutane & 0.22 & 1,2,4-trimethylbenzene & 2.11 \\
\hline 2,3-dimethylbutane & 0.71 & 1,3,5-trimethylbenzene & 0.79 \\
\hline n-heptane & 1.04 & o-ethyltoluene & 0.72 \\
\hline 2-methylhexane & 0.87 & m-ethyltoluene & 1.00 \\
\hline 3-methylhexane & 0.75 & p-ethyltoluene & 0.89 \\
\hline n-octane & 0.76 & Aldehydes & 0.86 \\
\hline methylheptanes (1) & 2.64 & formaldehyde & 0.47 \\
\hline n-nonane & 1.58 & acetaldeyde & 0.09 \\
\hline methyloctanes (2) & 0.65 & proprionaldehyde & 0.11 \\
\hline n-decane (3) & 1.32 & butyraldehyde & 0.08 \\
\hline methylnonanes (4) & 0.85 & i-butyraldehyde & 0.07 \\
\hline n-undecane (3) & 1.85 & valeraldehyde & 0.00436 \\
\hline n-duodecane (3) & 1.86 & benzaldehyde & 0.05 \\
\hline Alkenes & 8.5 & Ketones & 5.8 \\
\hline ethylene & 3.09 & acetone & 1.65 \\
\hline propylene & 1.11 & methyl-ethyl-ketone & 3.03 \\
\hline but-1-ene & 0.70 & methyl-isobutyl-ketone & 1.12 \\
\hline but-2-ene & 1.29 & Alcohols & 8.8 \\
\hline pent-2-ene & 0.97 & methanol & 0.50 \\
\hline pent-1-ene & 0.38 & ethanol & 8.33 \\
\hline 2-methylbut-1-ene & 0.21 & Esters & 1.7 \\
\hline 3-methylbut-1-ene & 0.25 & methyl-acetate & 0.12 \\
\hline 2-methylbut-2-ene & 0.47 & ethyl-acetate & 0.53 \\
\hline Alkynes & 2.1 & i-propyl-acetate & 0.26 \\
\hline butylene & 0.20 & n-butyl-acetate & 0.35 \\
\hline acetylene & 1.88 & i-butyl-acetate & 0.44 \\
\hline
\end{tabular}

(1) equally split between 2-methylheptane, 3-methylheptane and 4-methylheptane; (2) equally split between 2-methyloctane, 3-methyloctane and 4-methyloctane; (3) emission assigned to n-nonane; (4) emission assigned to methyl-octanes

unique representations in the generator code. Although a new version of the generator capable of treating cyclic species is under development, here the relatively few initial reactions for cyclic species were written manually using the schemes developed by Carter (2000). The non-cyclic secondary products from these reactions were then handled automatically by the generator.

The fully explicit description of the oxidation schemes for the 64 emitted VOC considered here would lead to a chemical scheme with approximately $4 \times 10^{10}$ species and $4 \times 10^{11}$ reactions, based on Eq. (1) of Aumont et al. (2005) (see Fig. 1). The solution of this fully explicit scheme would be problematic even in a zero-dimensional (box model) context. Therefore, an automated pre-reduction was applied using the generator code (note that this pre-reduction is a requirement unique to our generator scheme, while the reductions discussed in Sect. 4 are "usual" reductions used in common chemical schemes). The pre-reduction was carried out by replacing some secondary species by isomers already treated during the writing of the scheme. Every secondary species produced after three generation of non-radical products $\left(\mathrm{VOC}_{\text {prim }} \rightarrow \mathrm{VOC}_{\mathrm{sec}} \rightarrow \mathrm{VOC}_{\text {third }}\right)$ was compared with the list of species already included in the chemical scheme. Replacement of a given new secondary species by one on 


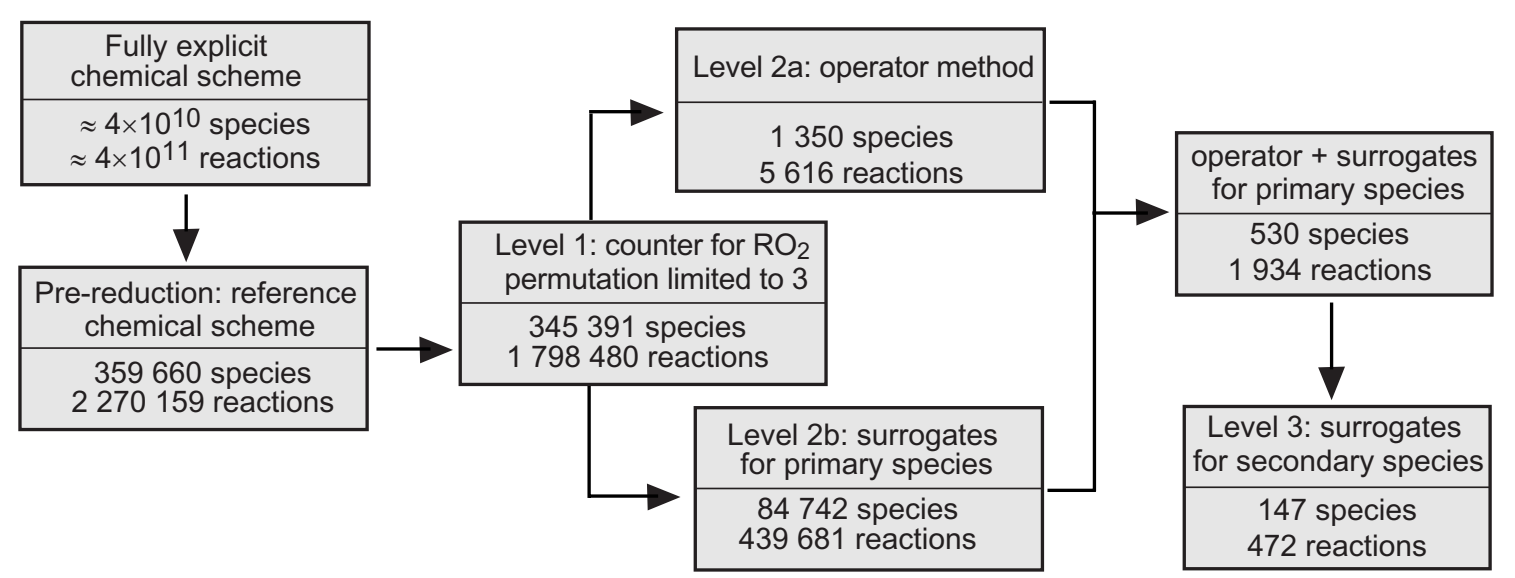

Fig. 1. Number of species and reactions in the schemes at different levels of reduction. Numbers for the fully explicit chemical scheme are estimated values.

the list was done if (i) it bears the same number of carbon atoms (ii) it contains the same functional groups and (iii) the positions of functional groups in the two species do not induce a particular reactivity for the molecule or its products (for example, a $\mathrm{C}-\mathrm{C}=\mathrm{C}-\mathrm{CO}$ - structure cannot be replaced by a $\mathrm{C}=\mathrm{C}-\mathrm{C}-\mathrm{CO}$ - structure, as these two isomers have distinct behaviour due to electron delocalization). The loss of accuracy from this pre-reduction was tested by comparing pre-reduced schemes with fully explicit schemes for hexane and for isoprene. The simulations were run over 5 days under four different $\mathrm{NO}_{\mathrm{x}}$ conditions (three cases in which the $\mathrm{NO}_{\mathrm{x}}$ level was respectively kept to a fixed value of $1 \mathrm{ppb}$, $100 \mathrm{ppt}$ and 10ppt and one case in which $\mathrm{NO}_{\mathrm{x}}$ evolved freely from an initial value of $1 \mathrm{ppb}$ ). For both hexane and isoprene, correlation coefficients were found to be greater than 0.9999 on the 1:1 line for $\mathrm{O}_{3}, \mathrm{NO}_{\mathrm{x}}, \mathrm{H}_{2} \mathrm{O}_{2}, \mathrm{OH}$ and $\mathrm{HO}_{2}$ when using this pre-reduction. For partly oxidized organic compounds, comparisons were made on a functional group basis. No significant differences between the explicit and pre-reduced mechanisms were observed during the first three simulated days and in all cases considered. However, a slight bias arose in the representation of some functional groups after three days (typically lesser than a few \%). Concentration timeseries for the various functional groups are provided in Appendix B (http://www.atmos-chem-phys.org/acp/ 5/2519/acp-5-2519-sp.zip). After this pre-reduction, the reference scheme describes the oxidation of the 67 primary VOC through more than 2 million reactions among 350000 species.

\section{Scenarios}

The effect of the reductions was tested using five scenarios representing various environmental conditions. Simulations were conducted for both summer and winter conditions.
A two-layer box model was used to represent some vertical mixing, while still allowing practical computation of the chemistry with both the explicit and the reduced chemical schemes.

\subsection{Moderately and highly polluted scenarios}

Two scenarios represent typical urban and polluted rural areas. The general conditions for these two scenarios are similar to those described by Aumont et al. (2003). Compounds are exchanged between the two layers (representing the continental boundary layer and the residual layer above it) during the diurnal variation of the boundary layer height. The top of the lower layer varies from $150 \mathrm{~m}$ during the night to $1000 \mathrm{~m}$ in the afternoon for the summer conditions, and from 150 to $500 \mathrm{~m}$ for the winter conditions. The top of the upper layer is fixed at 2000 and $1000 \mathrm{~m}$ for the summer and winter scenarios, respectively. Initial conditions for both layers are from Sillman et al. (1990) and represent typical rural concentrations. The residence time (or the flushing time) of the air inside the box is $6 \mathrm{~h}$ for the urban scenario and $36 \mathrm{~h}$ for the polluted rural scenarios, incoming air having concentrations equal to initial concentrations. The anthropogenic emissions of $\mathrm{NO}_{\mathrm{x}}$ and VOC are based on Sillman et al. (1990) and Bey et al. (2001), and correspond to averaged values for typical urban and rural areas. The speciation of hydrocarbon emissions is based on the inventory provided by Derwent and Jenkin (1991), as discussed above (see Table 1). Diurnal variations of anthropogenic $\mathrm{NO}_{\mathrm{x}}$ and VOC emissions were parameterized according to Hough (1986), as described in Bey et al. (2001). Biogenic emissions of $\mathrm{NO}_{\mathrm{x}}$ and VOC (isoprene and terpenes) were taken from Aumont et al. (2003) and varied with temperature and with solar radiation (isoprene only) according to the parameterizations given by Simpson et al. (1995). Deposition velocities were computed for each scenario using the model of Wesely (1989). Deposition was con- 
sidered for $\mathrm{SO}_{2}, \mathrm{O}_{3}, \mathrm{H}_{2} \mathrm{O}_{2}, \mathrm{NO}_{2}, \mathrm{NO}$ and $\mathrm{HNO}_{3}$. We used the categories 1 (mid summer with lush vegetation) and 3 (late autumn after frost, no snow) provided by Wesely (1989) to estimate the deposition velocities for the summer and winter scenarios, respectively. Actinic fluxes were computed using the TUV model (Madronich and Flocke, 1998) in which we introduced the optical properties of aerosol mixtures recommended by the World Climate Research Program (1986). Photolysis rates were calculated for $45^{\circ} \mathrm{N}$ under cloud-free conditions for a typical winter and summer day. Simulations were run over five days, corresponding to the time required to reach two nearly identical successive diurnal cycles for key species (e.g. $\mathrm{O}_{3}, \mathrm{NO}_{\mathrm{x}}, \mathrm{H}_{2} \mathrm{O}_{2}, \mathrm{OH}, \mathrm{HO}_{2}$ ). The $24 \mathrm{~h}$ diurnal profiles presented below are given for the fifth day.

Figure 2 shows the simulations obtained with the reference model for the urban and regional scenarios. These results are compared with those obtained using the SAPRC99 scheme (Carter, 2000), but with the same inorganic chemistry as the reference scheme (see Aumont et al., 2005). Also shown are typical diurnal profiles measured by the Paris air quality network (data available at http://www.airparif.asso.fr) at two locations: "Paris 18", an urban station away from major traffic influence, was chosen to be representative of the urban background atmosphere; and "Rambouillet", a rural station located $30 \mathrm{~km}$ south/west of Paris that can experience high ozone concentrations during summertime, was chosen to be representative of the regional scenario. Figure 2 shows very good agreement between the simulated concentrations with SAPRC99 and the reference scheme, and the comparison with measurements indicates that the chosen scenarios are reasonably representative of urban and regional conditions.

\subsection{Free relaxation of air masses}

Three other scenarios were built to test chemical schemes under low- $\mathrm{NO}_{\mathrm{x}}$ conditions. In order to begin the simulations with a VOC speciation representative of an aged air mass, these relaxation scenarios were initialized with the results from the moderately polluted scenario described above. Specifically, initial concentrations are taken at noon on the fifth day of the moderately polluted scenario. Two scenarios, summer and winter, were considered for relaxation of air masses in the boundary layer. Neither emissions nor advection nor variation of the mixing height are considered in these scenarios. However, deposition was considered for $\mathrm{SO}_{2}, \mathrm{O}_{3}, \mathrm{H}_{2} \mathrm{O}_{2}, \mathrm{NO}_{2}, \mathrm{NO}$ and $\mathrm{HNO}_{3}$. Deposition velocities were computed with surface category 9 , "water, both salt and fresh" (Wesely, 1989). Finally, another scenario was constructed for low pressure ( 540 mbar), low temperature $(256 \mathrm{~K})$ and low water vapor concentration. These values were taken from the US Standard Atmosphere 1976 for typical air mass at $5 \mathrm{~km}$. No deposition is considered for this scenario.

\section{Reduction methods}

Various reduction methods have been used historically for the development of simplified chemical schemes for 3-D chemistry transport models (e.g. the commonly used Carbon Bond, RACM, and SAPRC99). These methods generally involve the replacement of a subset of chemically similar species by a single, either explicit or generic species (surrogate or lumping methods), and by the introduction of pseudospecies (counters or operators) to drive chemical transformations which control the overall reactivity (e.g. radical propagation vs. termination) or the production of oxidants (e.g. NO $\rightarrow \mathrm{NO}_{2}$ conversions). These reductions have typically been applied manually to an initially more complete - but still not fully explicit - scheme. With the development of very large explicit mechanisms, such as the MCM (Jenkin et al., 2003) and the automatically generated mechanism used here, there is a need for a reduction methodology that can be automated for computer-based systematic reductions starting from these reference schemes. Furthermore, it is likely that a fully explicit scheme is a better benchmark for evaluating the accuracy of the reduced mechanism over a wide range of conditions.

The reduction methods tested in this work were automated to allow fast writing of reduced schemes and to facilitate modifications with future updates. The different levels of reduction are summarized on the Fig. 1. A short description of the methods is given below. More details concerning the reductions are given by Laval-Szopa (2003).

\subsection{Counter species for peroxy radical chemistry}

Organic peroxy radicals $\left(\mathrm{RO}_{2}\right)$ are among the most important and ubiquitous radical species formed in the atmospheric oxidation of both the initial hydrocarbons and the subsequent non-radical organic intermediates. The number of $\mathrm{RO}_{2}$ radicals is quite large in explicit schemes, being comparable to, and frequently larger than, the number of non-radical VOCs. Peroxy radicals react among themselves $\left(\mathrm{RO}_{2}+\mathrm{R}^{\prime} \mathrm{O}_{2}\right.$, the socalled permutation reactions), so that an explicit mechanism containing $n$ peroxy radicals will include $n(n+1) / 2$ permutation reactions. Furthermore, many of these reactions have multiple product pathways, so that the total number of permutation reactions can be exceedingly large. Madronich and Calvert (1990) noted that if the $\mathrm{RO}_{2}$ 's can be subdivided into a small number $m$ of reactivity classes ( $m=4$ in their case), a counter-based scheme that conserves both reaction rates and product identities can be used instead of the full set of permutation reactions. The number of reactions in their counter scheme increases linearly $(m \times n)$ rather than quadratically with $n$. Here, we use a similar counter method but with different numbers of reactivity classes.

The reference scheme (see Aumont et al., 2005) takes into account 9 reactivity classes for the permutation reactions. To reduce this number, different configurations for the reactivity 
- Urban summer scenario

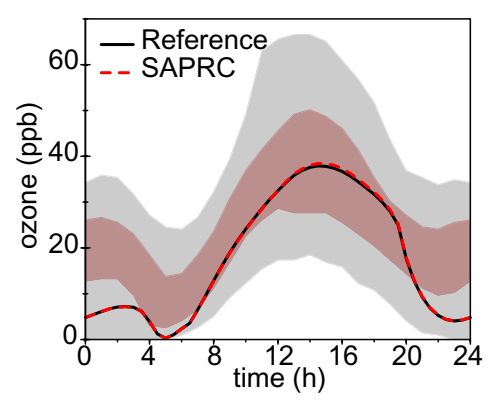

- Urban winter scenario

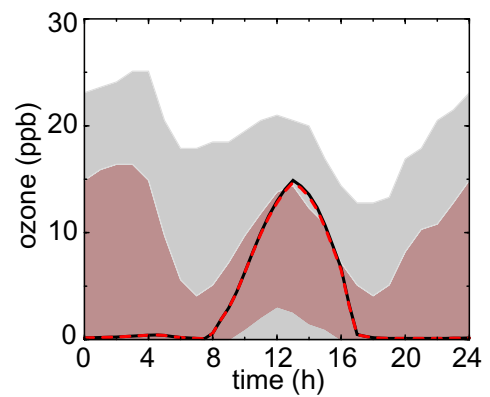

- Regional summer scenario

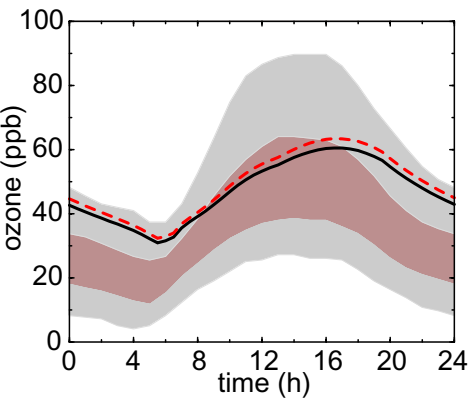

- Regional winter scenario

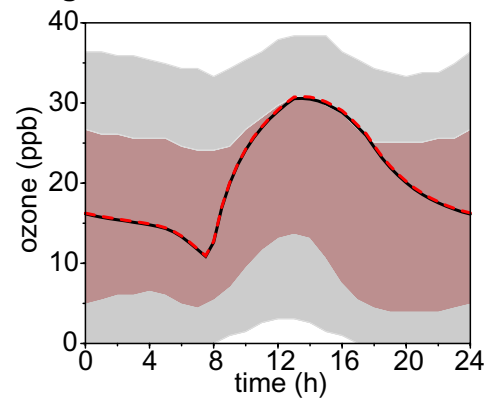

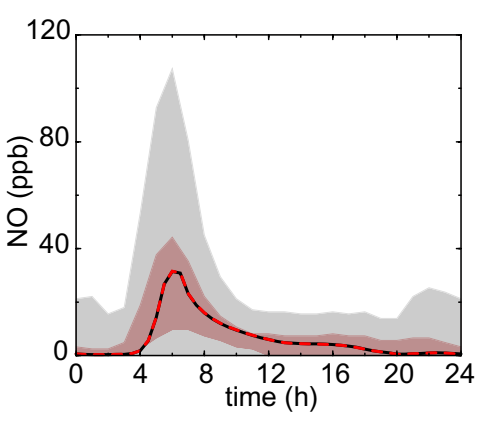
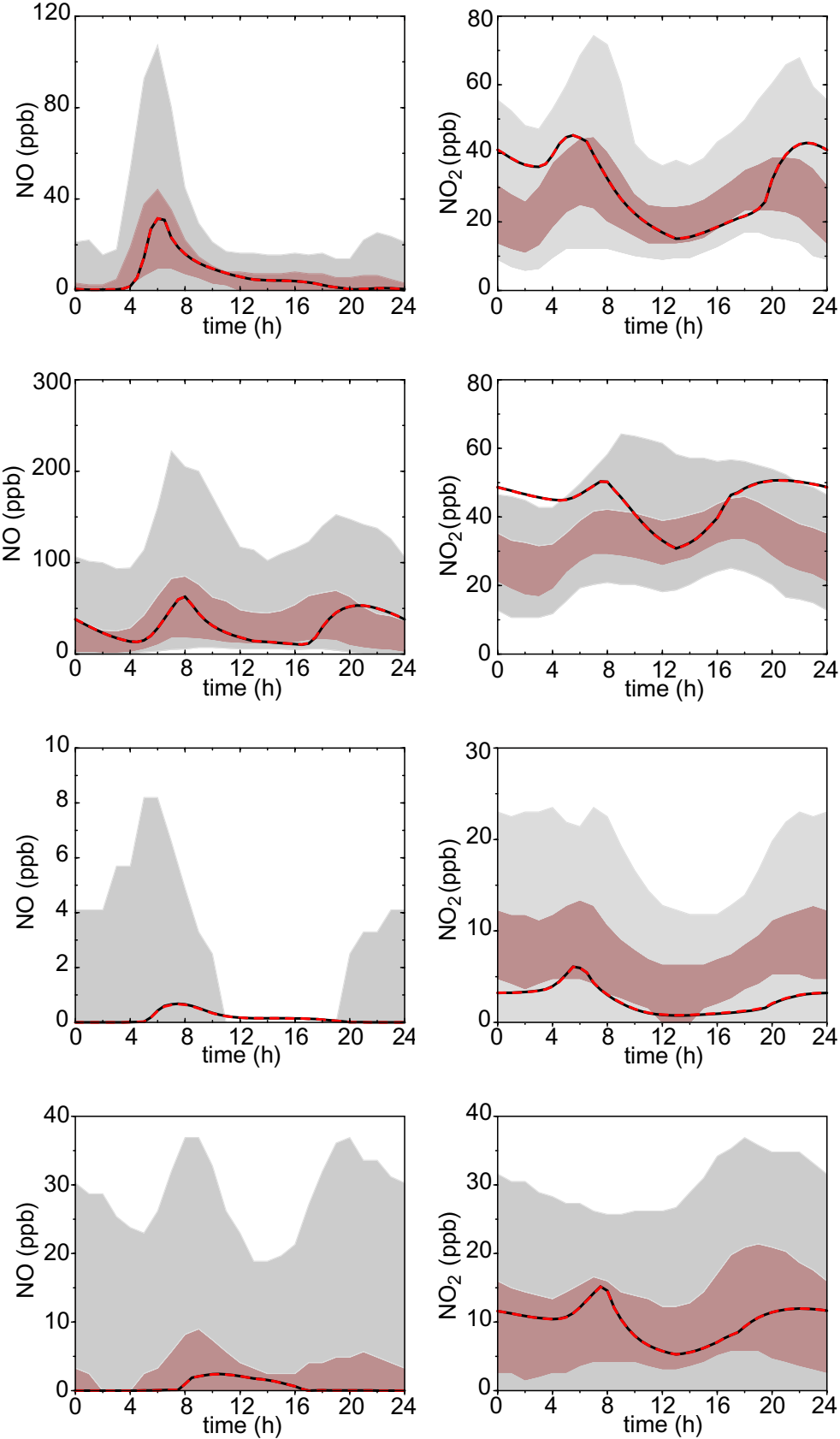

Fig. 2. Simulated mixing ratios of $\mathrm{O}_{3}, \mathrm{NO}$ and $\mathrm{NO}_{2}$ for the highly and moderately polluted scenarios simulated with the reference scheme (black line) and the SAPRC99 scheme (long dashed red line). The shaded areas are measurements (respectively in a Paris urban station and in a rural station in the suburbs of Paris, averaged over the years 1993-2001). The pale gray zones represent the 5 and 95 percentiles. The dark zones represent the 25 and 75 percentiles. In the regional winter scenario for $\mathrm{NO}$, the 5, 25, and most 75 percentiles are below the detection limit $(2.5 \mathrm{ppb})$ and are therefore not shown.

classes of peroxy radicals were tested for conditions similar to those described by Madronich and Calvert (1990) for the marine boundary layer. The effect of this simplification was tested by comparing the results obtained with those simulated when using all nine reactivity classes. A good agreement was found when using only 3 different reactivity classes instead of 9 in the explicit chemical scheme. These classes are:

1. Acyl-peroxys $\left(\mathrm{RCOO}_{2}+\mathrm{RO}_{2}\right)$ which react rapidly among themselves and with other peroxy 
Table 2. Biases due to the reduction by decreasing the number of peroxy recombination reactivity: regression parameters for inorganic species.

\begin{tabular}{ccc}
\hline \multicolumn{3}{c}{ Regression parameters } \\
Species & Slope & $\mathbf{R}^{2}$ \\
\hline $\mathrm{O}_{3}$ & 1.0001 & 1.0000 \\
$\mathrm{H}_{2} \mathrm{O}_{2}$ & 0.99983 & 1.0000 \\
$\mathrm{CO}$ & 1.0021 & 1.0000 \\
$\mathrm{CO}_{2}$ & 0.99890 & 1.0000 \\
$\mathrm{HNO}_{3}$ & 0.99190 & 0.99996 \\
$\mathrm{HNO}_{2}$ & 0.98982 & 0.99998 \\
$\mathrm{OH}_{+} \mathrm{HO}_{2}$ & 1.0008 & 0.99992 \\
$\mathrm{NO}_{\mathbf{x}}$ & 0.99452 & 0.99997 \\
\hline & &
\end{tabular}

radicals. A cross-reaction rate constant of $10^{-11}$ molecule ${ }^{-1} \mathrm{~cm}^{3} \mathrm{~s}^{-1}$ is taken for all $\mathrm{RCOO}_{2}+\mathrm{RO}_{2}$ reactions.

2. Peroxy radicals having self-reaction rate constant greater than $10^{-13}$ molecule ${ }^{-1} \mathrm{~cm}^{3} \mathrm{~s}^{-1}$ at $298 \mathrm{~K}$ are represented by a class of peroxy reacting with a single self-reaction rate constant of $1.2 \times 10^{-12}$ molecule ${ }^{-1} \mathrm{~cm}^{3} \mathrm{~s}^{-1}$ at $298 \mathrm{~K}$. This rate constant corresponds to that recommended by Lesclaux (1997) for the primary peroxy radical with a branching in the alpha-position.

3. Peroxy having a self-reactions rate constant less than $10^{-13}$ molecule ${ }^{-1} \mathrm{~cm}^{3} \mathrm{~s}^{-1}$ at $298 \mathrm{~K}$ for which selfreactions and cross-reactions are neglected. The neglect of these reactions also led to a reduction in the number of species (see Fig. 1).

The regression parameters for key inorganic species and the deviations for organic functional groups, relative to the scheme involving nine classes of peroxys, are presented in the Tables 2 and 3. For inorganic species, the grouping of peroxy radical classes has no significant impact on the simulated concentrations. For organic functions, maximums biases due to this reduction never exceed a few percent. This reduction decreases significantly the number of reactions (by $20 \%$ ) but induces only a slight decrease in the number of species $(4 \%)$.

\subsection{Operator species for peroxy radical chemistry}

As stated in the previous section, the representation of VOC degradation requires a large number of peroxy radicals to describe the many possible different degradation pathways. The "chemical operator" method (Gery et al., 1989; Carter, 1990; Aumont et al., 1996) was developed to decrease the number of required peroxy radicals. In this approach, when
Table 3. Biases due to the reduction by decreasing the number of peroxy recombination reactivity: maximum relative deviations for the organic functions.

\begin{tabular}{lr}
\hline Function & $\begin{array}{r}\text { Maximum relative } \\
\text { deviation }(\%)\end{array}$ \\
\hline Hydroperoxyde & -3.9 \\
Alcohol & 5.9 \\
Aldehyde & 1.2 \\
Nitrate & 2.3 \\
Peroxy acid & 3.5 \\
Carboxylic Acid & -3.8 \\
\hline
\end{tabular}

a peroxy radical is formed, instead of being represented explicitly, it is replaced by (i) the oxygenated products which would be ultimately formed under high $\mathrm{NO}_{\mathrm{x}}$ concentration and (ii) some artificial species (called "chemical operators") which are used to represent the net effects of the peroxy radical reactions on the $\mathrm{NO}$ consumption, $\mathrm{NO}_{2}$ formation, $\mathrm{HO}_{2}$ consumption and formation, and nitrate or hydroperoxide formation. This method relies on the following assumptions: (1) the rate of the organic oxidation process is limited by the initiation of the organic radical chain, and (2) the effect on inorganic budgets ( $\mathrm{NO}$ to $\mathrm{NO}_{2}$ conversion, $\mathrm{HO}_{2}$ consumption and/or regeneration, NO consumption during formation of nitrate, etc.) are redundant for various VOCs despite their structural differences. With these two assumptions, a generalized reaction can be written for each VOC, in which product yields represent the organic sequences up to the secondary non-radical organic products resulting from the oxidation of the parent VOC considered. In these generalized reactions, chemical operators are used to drive inorganic transformations, such as $\mathrm{NO}$ to $\mathrm{NO}_{2}$ conversion or $\mathrm{HO}_{2}$ radical regeneration. Here, we automated the method and we modified the operator method to extend its accuracy to low $\mathrm{NO}_{\mathrm{x}}$ conditions.

Each oxidation of an organic compound is written by a global reaction as follows:

$$
\begin{aligned}
\text { VOC }+ \text { oxidant (or photon) } \rightarrow & \\
& a_{1} \operatorname{VOC}_{\mathrm{sec}, 1}+\cdots+a_{n} \mathrm{VOC}_{\mathrm{sec}, n}+ \\
& b_{1}<\operatorname{peroxy}_{1}>+\cdots+b_{n}<\operatorname{peroxy}_{\mathrm{n}}>
\end{aligned}
$$

The various terms of the reaction are described below. The practical implementation of this method is illustrated in Figs. 3 and 4 for propane.

The left side of the reaction describes the initiation of the oxidation of each explicit non-radical VOC. This VOC could equally well be a primary (emitted) VOC or one formed by subsequent chemistry (secondary species). The inorganic oxidant can be $\mathrm{OH}, \mathrm{O}_{3}, \mathrm{NO}_{3}$ or the oxidation can be initiated by photolysis. $\mathrm{VOC}_{\mathrm{sec}, 1}$ trough $\mathrm{VOC}_{\mathrm{sec}, \mathrm{n}}$ represent the first generation of non-radical secondary organic products created 


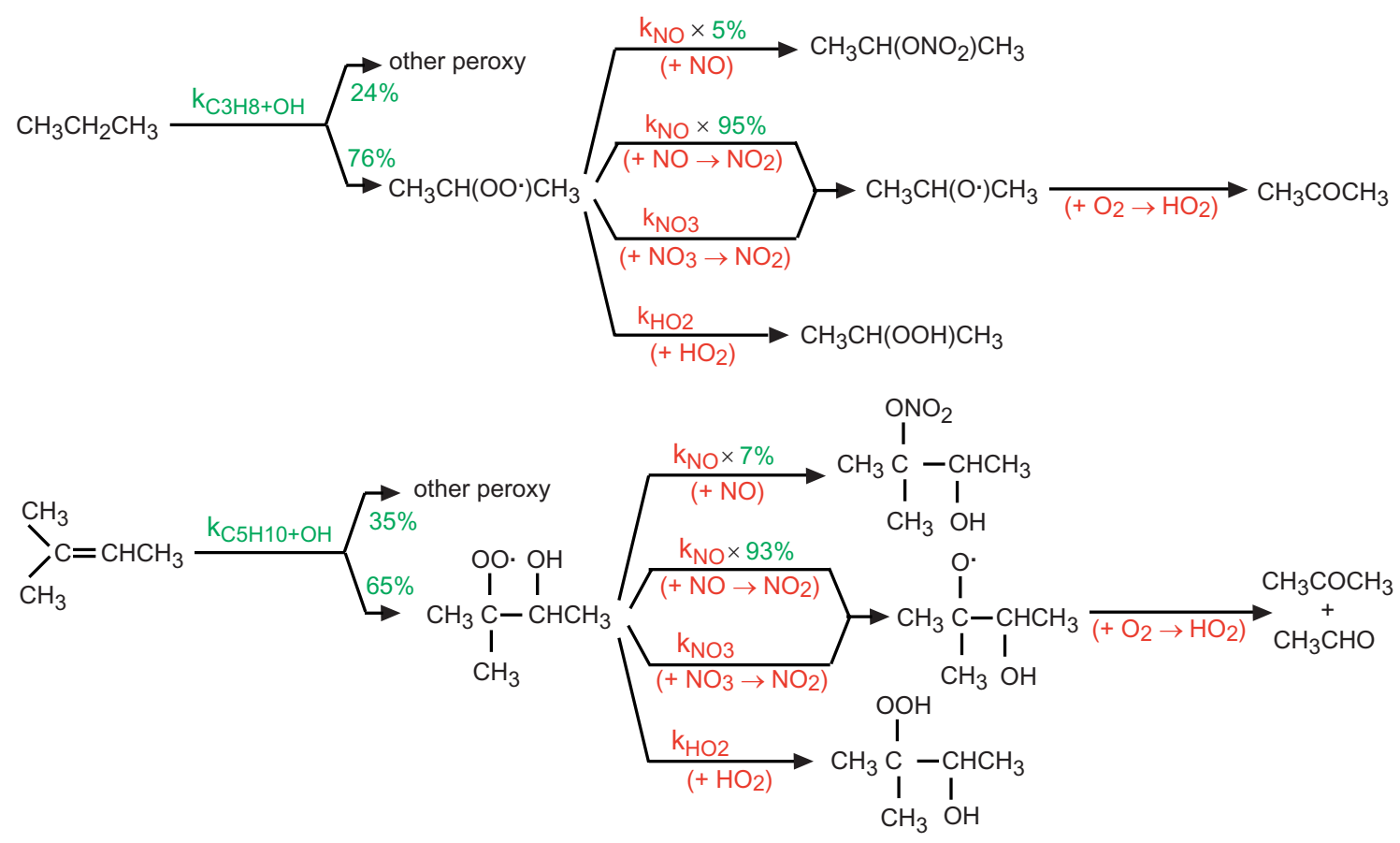

Fig. 3. Illustration of the similarities in the oxidation of two different VOCs. In green: kinetic elements differing in the two chains. In red: redundant elements in the two chains. For simplicity, peroxy permutation reactions are not shown in the figure.

by the oxidation of the VOC. They are explicit non-radical VOCs, formed by the major reaction pathways of the radicals produced from the original VOC. The $<$ peroxy $>$ operators and coefficients $a_{1}-a_{n}$ and $b_{1}-b_{n}$ are discussed below.

Reaction (R1) is intended to replace a large number of explicit reaction pathways that transform the initial VOC to its first generation non-radical products. Multiple transformation pathways are common, e.g. from $\mathrm{OH}$ attack at different positions of the initial VOC, as well as from branching of the subsequent reactions of peroxy and alkoxy radicals. With some assumptions, the yields of the first generation products can be estimated from the branching ratios of all the explicit reactions in each possible pathway. For example, Calvert and Madronich (1987) estimated (manually) the yields of the first generation products of many hydrocarbons, separately for high and low $\mathrm{NO}_{\mathrm{x}}$ conditions. Here, we take advantage of the explicit generator code to write, for each initial VOC, all the possible reaction pathways. This allows us to identify unambiguously the first generation non-radical products $\left(\mathrm{VOC}_{\mathrm{sec}, 1}\right.$ trough $\left.\mathrm{VOC}_{\mathrm{sec}, \mathrm{n}}\right)$ and to calculate their respective yields $a_{1}-a_{n}$, also accounting for the possibility that multiple pathways can lead to the same product. Because this procedure is automated, products and yields are easily computed not only for initial hydrocarbons, but also for all of the intermediate non-radical VOCs. Two simplifying assumptions were made: all branching ratios were computed at a fixed temperature $(298 \mathrm{~K})$, and branching ratios for $\mathrm{RO}_{2}$ reactions were computed assuming high $\mathrm{NO}_{\mathrm{x}}$ conditions. These two assumptions are required to compute fixed $a_{i}$ yields, i.e. not varying with physical or chemical conditions. While the high $\mathrm{NO}_{\mathrm{x}}$ assumption may appear severe, it should be noted that (i) high $\mathrm{NO}_{\mathrm{x}}$ is only assumed for the derivation of the terms on the right side of Reaction (R1), not for the remainder of the chemical scheme; (ii) organic nitrate formation is treated separately; (iii) degradation of explicit organic peroxides would mostly lead to the same products as the high $\mathrm{NO}_{\mathrm{x}}$ scheme (although with some delay); and (iv) formation of surrogate (but not explicit) organic peroxides is effected by the $<$ peroxy $>$ operator chemistry (see below). Thus, we anticipate that the reduced mechanism should remain reasonably accurate even at low $\mathrm{NO}_{\mathrm{x}}$ conditions.

The peroxy operators (denoted $<$ peroxy $>$ ) are mass-less peroxy-like radical species introduced to represent the effects of Reaction (R1) on radical and $\mathrm{NO}_{\mathrm{x}}$ budgets, approximating the effects of the explicit peroxy radicals and their descendant explicit alkoxy radicals. These $<$ peroxy $>$ operators are not simply substituted for explicit peroxy radicals on a oneto-one basis, but rather different operators are used to represent different reaction pathways. For example, each explicit peroxy radical is replaced by at least two (and often more see below) $<$ peroxy $>$ operators, to represent separately the formation of alkoxy radicals and the formation of organic nitrates. However, and this is the important point, the same set of relatively few $<$ peroxy $>$ operators can be used to replace 


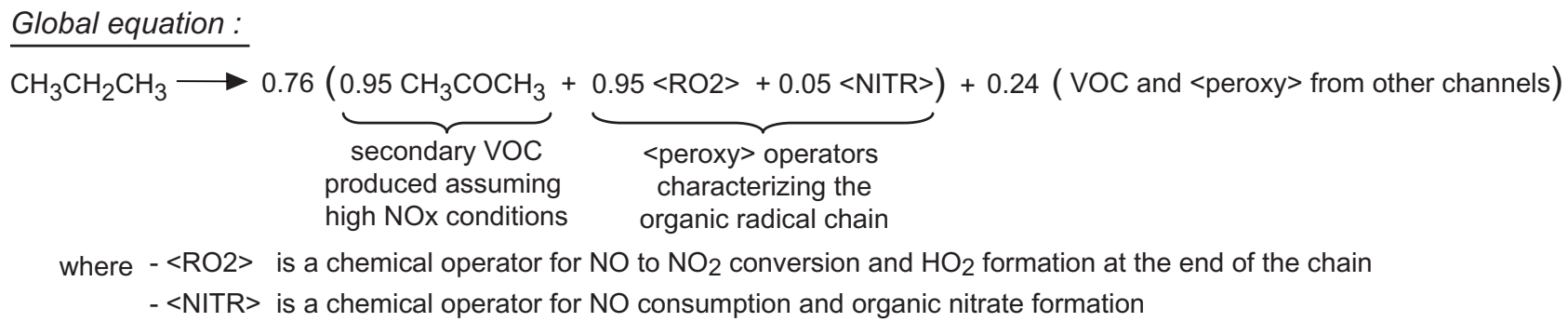

$<$ peroxy> operator chemistry :
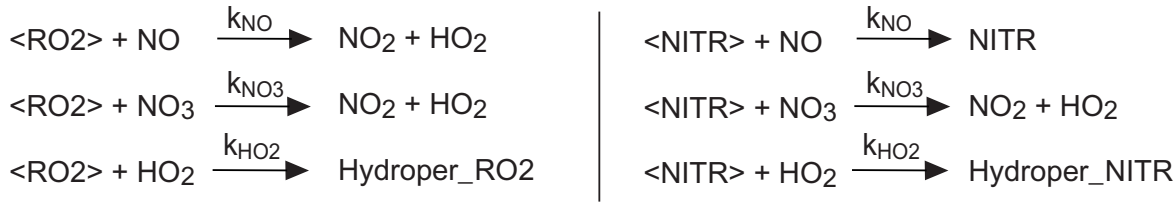

where - Hydroper_RO2 and Hydroper_NITR are carbon-less surrogates hydroperoxides (see text)

- NITR is a surrogate for organic nitrate

Fig. 4. Illustration of the peroxy operator approach for propane. The yields in the global equation are based on the branching ratio shown Fig. 3. For simplicity, figure does not show peroxy permutation reactions and reactions from other, minor, channels.

the many different explicit peroxy radicals arising from different initial VOCs.

Construction of different $<$ peroxy $>$ types is made automatically from the previously generated explicit scheme, and is based on several criteria:

1. $\mathrm{CH}_{3} \mathrm{O}_{2}$ radicals are treated explicitly.

2. Each explicit alkylperoxy radical is replaced by an operator $<$ NITR $>$ to represent nitrate formation, and one or more operators to describe the $\mathrm{NO} \rightarrow \mathrm{NO}_{2}$ conversion path. The nitrate formation reaction is then represented as:

$$
<\mathrm{NITR}>+\mathrm{NO} \rightarrow \mathrm{NITR}
$$

where NITR is a surrogate species representing organic nitrates. In principle it is straightforward to retain detailed information about the nitrates formed, e.g. with the same number of carbon atoms as the explicit nitrate, using different nitrate operators $(<$ NITR1 $>$, $<$ NITR2 $>$, etc.) to give different nitrate products (NITR1, NITR2, etc.). However this high detail is not retained in the final reduced scheme presented here, and only 3 different nitrate operators are used. Note that by producing nitrate from the $<$ NITR $>+\mathrm{NO}$ reaction (instead of in Eq. R1), we ensure that this will occur only when sufficient $\mathrm{NO}$ is present. Operators for $\mathrm{NO} \rightarrow$ $\mathrm{NO}_{2}$ conversions are further categorized according to the co-product of the reaction with $\mathrm{NO}$, as follows:

$$
\begin{aligned}
<\mathrm{RO} 2>+\mathrm{NO} & \rightarrow \mathrm{NO}_{2}+\mathrm{HO}_{2} \\
<\mathrm{OHRO} 2>+\mathrm{NO} & \rightarrow \mathrm{NO}_{2}+\mathrm{OH}
\end{aligned}
$$

$$
\begin{aligned}
&<2 \mathrm{NO} 2>+\mathrm{NO} \rightarrow \mathrm{NO}_{2}+\mathrm{NO}_{2} \\
&<\mathrm{NONO} 2>+\mathrm{NO} \rightarrow \mathrm{NO}_{2} \\
&<\mathrm{NONO} 2 \_\mathrm{C}>+\mathrm{NO} \rightarrow \mathrm{NO}_{2}+\mathrm{CH}_{3} \mathrm{O}_{2}
\end{aligned}
$$

These distinctions ensure that the $\mathrm{NO}_{\mathrm{x}}$ and radical budgets are kept similar to the original explicit scheme.

3. An additional distinction is made between radicals that react rapidly or slowly in peroxy radical permutations (see Sect. 4.1). The < peroxy $>$ operators defined by the Reactions (R3-R7) were therefore split into 2 classes to take this distinction into account.

4. In many cases, the Reaction (R3) is insufficient to represent the number of $\mathrm{NO} \rightarrow \mathrm{NO}_{2}$ conversions that ultimately leads to $\mathrm{HO}_{2}$. For example, if the product of the $<\mathrm{RO} 2>+\mathrm{NO}$ reaction is a large alkoxy radical, its isomerization can lead to new organic peroxy radical rather than immediately to $\mathrm{HO}_{2}$. The SAPRC99 scheme uses a parallel treatment, wherein Reaction (R6) is added to the scheme to represent any additional peroxy formation and the impact on the $\mathrm{NO}_{\mathrm{x}}$ budget (see Fig. 5). Under low $\mathrm{NO}_{\mathrm{x}}$ conditions, this parallel treatment induces (i) an overestimation of $\mathrm{NO} \rightarrow \mathrm{NO}_{2}$ conversions and of $\mathrm{HO}_{2}$ production, and (ii) an underestimations of organic hydroperoxide formation. Here, the operator method was tailored to various conditions including low $\mathrm{NO}_{\mathrm{x}}$ conditions, using additional peroxy operators in which a sequential treatment of successive $\mathrm{RO}_{2}$ formation is introduced:

$<\mathrm{RO} 2_{\mathrm{n}}>+\mathrm{NO} \rightarrow \mathrm{NO}_{2}+<\mathrm{RO} 2_{\mathrm{n}-1}>$ 


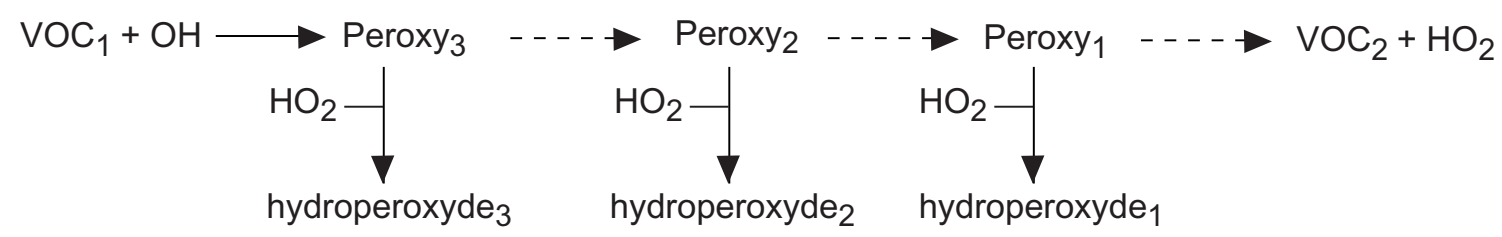

\begin{tabular}{|c|c|c|}
\hline \multicolumn{2}{|c|}{ Sequential treatment } & Parallel treatment \\
\hline $\mathrm{VOC}_{1}+\mathrm{OH}$ & $\mathrm{VOC}_{2}+<\mathrm{RO}_{2}>$ & $\mathrm{VOC}_{1}+\mathrm{OH} \quad \mathrm{VOC}_{2}+\left\langle\mathrm{RO}_{2}{ }_{1}\right\rangle+2\left\langle\mathrm{NONO}_{2}\right\rangle$ \\
\hline$<\mathrm{RO}_{2}>+\mathrm{NO}$ & $<\mathrm{RO}_{2}>+\mathrm{NO}_{2}$ & $<\mathrm{RO}_{2}>+\mathrm{NO} \quad \mathrm{HO}_{2}+\mathrm{NO}_{2}$ \\
\hline$<\mathrm{RO}_{3}>+\mathrm{HO}_{2}$ & 2 hydroper $_{3}$ & $<\mathrm{RO}_{2}>+\mathrm{HO}_{2} \quad$ hydroper \\
\hline$<\mathrm{RO}_{2}>+\mathrm{NO}$ & $<\mathrm{RO}_{2}>+\mathrm{NO}_{2}$ & $<\mathrm{NONO}_{2}>+\mathrm{NO} \quad \mathrm{NO}_{2}$ \\
\hline$<\mathrm{RO}_{2}>+\mathrm{HO}_{2}$ & hydroper 2 & $<\mathrm{NONO}_{2}>+\mathrm{HO}_{2} \quad$ hydroper \\
\hline$<\mathrm{RO} 2_{1}>+\mathrm{NO}$ & $\mathrm{HO}_{2}+\mathrm{NO}_{2}$ & \\
\hline$<\mathrm{RO}_{2}>+\mathrm{HO}_{2}$ & hydroper $_{1}$ & \\
\hline
\end{tabular}

Fig. 5. Schematic comparison of the parallel and sequential treatments in the operator method. For simplicity, formation of organic nitrates is not shown.

until, for $\mathrm{n}=1$, the $<\mathrm{RO} 2_{\mathrm{n}-1}>$ operator is replaced by $\mathrm{HO}_{2}$. Compared to the parallel approach, the sequential treatment provides a more accurate representation of the radical organic chains but requires an increased number of operators. In practice, we limit $n \leq 3$. Whenever a sequence includes the succesive production of more than three peroxy radicals, the first generations of $\mathrm{NO} / \mathrm{NO}_{2}$ conversions are arbitrarily treated in parallel and the last three generations are treated sequentially. The parallel treatment was also used for the pathways leading to nitrate formation.

5. Acylperoxy radicals are treated separately from alkyperoxy radicals. The explicit organic products written in the global Reaction (R1) are those arising from $\mathrm{RC}(=\mathrm{O}) \mathrm{O}_{2}+\mathrm{NO}$ reaction in the explicit scheme. The associated operator, $<\mathrm{RO} 2 \_\mathrm{A}>$, converts $\mathrm{NO}$ to $\mathrm{NO}_{2}$ and produces the appropriate peroxy radical:

$<$ RO2_A $>+\mathrm{NO} \rightarrow \mathrm{NO}_{2}+<$ peroxy $>$

Nevertheless, in ambient air, the evolution of acyl peroxy depends notably on the $\mathrm{NO} / \mathrm{NO}_{2}$ ratio, which controls the formation of PAN-type species. The formation of PAN is given by the reaction:

$<\mathrm{RO} 2 \_\mathrm{A}>+\mathrm{NO}_{2} \rightarrow$ PANs

where PANs is a carbon-less peroxy acyl nitrate surrogate for PAN like compounds.

Finally, we note that the $<$ peroxy $>$ and $<$ acylperoxy $>$ operators undergo all of the other reactions that explicit peroxy radicals participate in. For example, for the $<\mathrm{RO} 2_{\mathrm{n}}>$ operator, additional reactions are:

$$
\begin{aligned}
&<\mathrm{RO} 2_{\mathrm{n}}>+\mathrm{HO}_{2} \rightarrow \text { Hydroper_RO } 2_{\mathrm{n}} \\
&<\mathrm{RO} 2_{\mathrm{n}}>+\mathrm{NO}_{3} \rightarrow \mathrm{NO}_{2}+<\mathrm{RO} 2_{\mathrm{n}-1}> \\
&<\mathrm{RO} 2_{\mathrm{n}}>+\mathrm{RO} 2_{\text {count }} \rightarrow c<\mathrm{RO} 2_{\mathrm{n}-1}>
\end{aligned}
$$

where Hydroper $\mathrm{RO} 2_{\mathrm{n}}$ are organic peroxide surrogates, $\mathrm{RO} 2_{\text {count }}$ are the counter species for the $\mathrm{RO}_{2}+\mathrm{RO}_{2}$ permutation reactions (see Sect. 4.1) and $c$ is a branching ratio computed from the explicit scheme.

Additional surrogate non radical species were introduced to take into account the formation of organic functionalities not generated by the $\mathrm{RO}_{2}+\mathrm{NO}$ reactions, like PANs (e.g. R10), hydroperoxides (e.g. R11), acids, and peracids (e.g. the reactions of peroxyacyl with $\mathrm{HO}_{2}$ ). Although these are zero-carbon species, they undergo chemical processing similar to their explicit analogs. For example, surrogate hydroperoxides can react with $\mathrm{OH}$ or can be photodissociated and reform radical species $\left(\mathrm{OH}, \mathrm{HO}_{2}\right.$ or $\left.<\mathrm{RO} 2>\right)$ with the rate constant corresponding to that of the attack of $\mathrm{OH}$ on the -OOH function, much like explicit organic hydroperoxides. The PAN-like species can regenerate $\mathrm{NO}_{2}$ at the same rate as peroxy acetyl nitrate by decomposition and photolysis.

The coefficients $b_{1}-b_{n}$ are calculated on the same way as $a_{1}-a_{n}$, i.e. from the explicit reference mechanism by multiplication of branching ratios computed at $298 \mathrm{~K}$ and high $\mathrm{NO}_{\mathrm{x}}$ conditions (see coefficients in the Fig. 3 and 4 for the oxidation of propane). Each peroxy radical pathway (up to the production of non radical organic species) is assigned to the corresponding $<$ peroxy $>$ operators with a yield equal to the contribution that the particular pathway makes to the removal of the peroxy being considered (see example in Fig. 4).

The writing of the global equation for each VOC, the creation of the appropriate operators and the writing of their 
chemistry are done automatically. The application of this method to the reference scheme results in a very strong decrease of the number of species in the chemical scheme (1350 versus $3.6 \times 10^{5}$ ) using approximately 40 different operators.

\subsection{Surrogates for primary VOCs}

A common reduction technique is based on replacing the explicit primary VOC's, which can be numerous near anthropogenic sources, by a much smaller number of "lumped" or "surrogate" species. Lumped species are used to represent the average behaviour of a group of compounds, e.g. the virtual species ALK_L representing the average properties of larger alkanes, while surrogate species are explicit species assumed to represent selected similar compounds, e.g. propionaldehyde as a surrogate for all large aldehydes. Whether a lumping or surrogate approach is used, the choices are not unique, and each method can introduce substantial errors, e.g. mass conservation, differences in the temporal evolution of reactivity, and product yields. Here, we develop and test a surrogate scheme which yields good accuracy for predictions of $\mathrm{O}_{3}$, and is relatively simple to implement in 3-D models.

Primary species were grouped by their structure and reactivity with $\mathrm{OH}$, as shown in Table 4. Each group is represented in the reduced scheme by a single surrogate species from that group. Molecules were assigned to their group surrogate based on the following criteria:

1. The usual classification of the primary species as alkane, alkene, aromatic, aldehyde or ester. This grouping accounts for major differences in the initial reaction pathways $\left(\mathrm{OH}\right.$ and $\mathrm{NO}_{3}$ abstraction or addition, $\mathrm{O}_{3}$ addition, photolysis) and therefore also in the nature of secondary products.

2. The presence of neo or iso structure of the molecule. Iso structures, but not neo structures, are potentially strong sources of acetone, which may have a special significance in free tropospheric radical budgets (e.g. Jaegle et al., 2001).

3. Grouping of rate constants with $\mathrm{OH}$ falling within a factor of 2, with rate constant thresholds (see Table 4) taken from Middleton et al. (1990). This criterion differs from others mainly in that only this coarse $\mathrm{OH}$ reactivity grouping is used, and no additional $\mathrm{OH}$ reactivity weighting is performed within a group. In-group reactivity weighting, e.g. as used by SAPRC99, RACM, introduces significant complications because the reaction kinetics and branching ratios must be adapted to each case (e.g. domain or length of simulation). The coarse grouping used here has the advantage that the chemistry (kinetics and branching ratios) of the species used as surrogate is fixed and does not depend on the burdens of the primary pollutants. It is unclear a priori whether the advantages of detailed weighting methods outweigh the simplicity of our approach which uses a fixed chemical scheme. However, comparisons between the reduced and full scheme (see below) seem to justify our simpler approach.

4. For alkanes and aromatics, the mass of carbon is conserved by multiplying the emission of the real species by the ratio of the number of carbons in the real species to that in the surrogate species. An important issue in representing hydrocarbons is the number of potential $\mathrm{NO}$ to $\mathrm{NO}_{2}$ conversions that can occur. For example for alkanes, this is equal to the number of $\mathrm{C}-\mathrm{C}+\mathrm{C}-\mathrm{H}$ bonds (e.g. Jenkin et al., 2002). Thus, conservation of carbon also partly ensures the correct number of $\mathrm{NO} \rightarrow \mathrm{NO}_{2}$ conversions.

5. For alkenes, esters, and aldehydes, the reactivity mainly comes from those functional groups. For these reasons, the number of emitted functional groups is conserved and any surplus of carbon is added to butane emissions.

6. Species containing 2 or 3 carbon atoms have low reactivity and the description of their chemistry does not require many species. Therefore no surrogates were used for these species.

The assignment to surrogate species was performed manually for the 64 primary species selected for this study. Nevertheless, the procedure described above follows systematic rules which can readily be implemented into a computer algorithm to provide, for example, an interface between emission inventories and the chemical scheme.

It should be noted that the species used as surrogates no longer have any physical meaning and must rather be seen has virtual entities (i.e. a parameter of the model) for which a straight comparison with measurement might be meaningless. It would however still be appropriate to compare the modelled concentration of a surrogate with the measured sum of the explicit species that it represents. The number of species and reactions following this reduction is presented Fig. 1.

\subsection{Surrogates for secondary VOC}

A final reduction was achieved by replacing many secondary VOCs by fewer surrogate VOCs having similar reactivities. Compared to the primary VOCs discussed in the previous section, the selection of surrogates for secondary VOCs is more complex because of the presence of various functional groups (e.g. - $\mathrm{OH}$ for alcohols, $-\mathrm{ONO}_{2}$ for nitrates, etc.), often more than one per molecule. Our strategy was to retain the most reactive functional groups and to conserve carbon, both of which lend themselves to automated algorithms and thus did not require manual treatment. Other approaches are also possible and could be easily automated if based on consistent rules. Note that surrogate species are only used here for $\mathrm{C}_{>3}$ species, while $\mathrm{C}_{\leq 3}$ are kept explicitly. 
Table 4. Primary species grouping: on the left, grouping criteria for each species family (kinetic rates and structural particularities), on the right, the retained surrogate species and the species grouped into these surrogate species.

\begin{tabular}{|c|c|c|c|}
\hline $\begin{array}{l}\text { grouping criteria } \\
\text { Reactivity } \\
\left(k \text { in molecule }{ }^{-1} \mathrm{~cm}^{3} \mathrm{~s}^{-1}\right)\end{array}$ & $\begin{array}{l}\text { Particular } \\
\text { distinction }\end{array}$ & Surrogate species & $\begin{array}{l}\text { Species grouped into } \\
\text { surrogate species }\end{array}$ \\
\hline \multicolumn{4}{|l|}{ Alkanes } \\
\hline \multirow{2}{*}{$k_{O H}<3.33 \times 10^{-12}$} & n-alkanes & n-butane & n-butane \\
\hline & i-alkanes & i-butane & i-butane, 2,2-dimthylbutane \\
\hline \multirow[t]{2}{*}{$3.33 \times 10^{-12}<k_{O H}<6.66 \times 10^{-12}$} & n-alkanes & n-hexane & n-pentane, n-hexane \\
\hline & i-alkanes & 2-methylpentane & $\begin{array}{l}\text { i-pentane, 2-methylpentane, } \\
\text { 2,3-dimethylpentane }\end{array}$ \\
\hline \multirow[t]{5}{*}{$6.66 \times 10^{-12}<k_{O H}<1.33 \times 10^{-11}$} & n-alkanes & n-octane & n-heptane, 3-methylhexane, \\
\hline & & & $\begin{array}{l}\text { n-octane, 4-methylheptane, } \\
\text { 3-methylheptane, n-nonane, }\end{array}$ \\
\hline & & & 3-methyloctane, 4-methyloctane \\
\hline & i-alkanes & 2-methylheptane & 2-methylhexane, \\
\hline & & & 2-methylheptane, 2-methyloctane \\
\hline \multicolumn{4}{|l|}{ Alkenes } \\
\hline \multirow[t]{2}{*}{$k_{O H}<5 \times 10^{-11}$} & $\mathrm{CH}_{2}=\mathrm{CH}-\mathrm{R}$ & but-1-ene & but-1-ene, pent-1-ene \\
\hline & & & 3-methylbut-1ene \\
\hline \multirow[t]{3}{*}{$k_{O H}>5 \times 10^{-11}$} & $\mathrm{R}-\mathrm{CH}=\mathrm{CH}-\mathrm{R}^{\prime}$ & but-2-ene, & but-2-ene, pent-2ene \\
\hline & $\mathrm{CH}_{2}=\mathrm{C}<$ & 2-methylbut-1-ene & 2-methylbut-1-ene \\
\hline & $\mathrm{R}-\mathrm{CH}=\mathrm{C}<$ & 2-methylbut-2-ene & 2-methylbut-2-ene \\
\hline \multicolumn{4}{|l|}{ Aromatics } \\
\hline \multicolumn{2}{|l|}{$k_{O H}<6.00 \times 10^{-12}$} & toluene & toluene, n-propyl-benzene \\
\hline \multicolumn{2}{|l|}{$6.00 \times 10^{-12}<k_{O H}<1.33 \times 10^{-11}$} & ethyl-toluene & $\begin{array}{l}\text { ethylbenzene, i-propylbenzene, } \\
\text { o-ethyltoluene, p-ethyltoluene }\end{array}$ \\
\hline \multirow{4}{*}{\multicolumn{2}{|c|}{$1.33 \times 10^{-11}<k_{O H}$}} & 1,2,4-trimethylbenzene & o-xylene, m-xylene, p-xylene, \\
\hline & & & 1,2,3-trimethylbenzene, \\
\hline & & & 1,2,4-trimethylbenzene, \\
\hline & & & 1,3,5-trimethylbenzene \\
\hline \multicolumn{4}{|l|}{ Aldehydes } \\
\hline & & butyraldehyde & butyraldehyde, valeraldehyde \\
\hline \multicolumn{4}{|l|}{ Esters } \\
\hline$k_{O H}<3.33 \times 10^{-12}$ & n-acetates & ethylacetate & ethylacetate \\
\hline \multirow[t]{2}{*}{$k_{O H}>3.33 \times 10^{-12}$} & n-acetates & n-butylacetate & n-butylacetate \\
\hline & i-acetates & i-propylacetate & i-propylacetate, i-butylacetate \\
\hline
\end{tabular}

${ }^{\star}$ for alkanes, distinction between species capable to produce acetone or not

For monofunctional species, a simple surrogate containing the same functional group was used. Methyl ethyl ketone (MEK) and 2-hexanone were respectively used for $\mathrm{C}_{<6}$ and $\mathrm{C}_{\geq 6}$ linear ketones. Similarly, methyl isobutyl ketone and methyl isopentyl ketone were used for $\mathrm{C}_{<6}$ and $\mathrm{C}_{\geq 6}$ branched ketones. Propanal was used for higher aldehydes. The $\mathrm{C}_{\leq 4}$ nitrates were assigned to 2-propyl nitrate.
For $\mathrm{C}_{\geq 5}$ nitrates, two different surrogates are used (denoted NITR01 and NITR02 in Appendix A; see supplemental material: http://www.atmos-chem-phys.org/acp/5/2519/acp5-2519-sp.zip), depending on their $\mathrm{OH}$ reactivity to distinguish short term and long term $\mathrm{N}$ reservoir. The products of NITR01 and NITR02 reactions are assumed to equal those resulting from 2-pentyl nitrate. Currently, any excess carbon 
is represented using a simple counter species but could easily be assigned to a reactive species (e.g. butane). Simulations indicate that this is a small correction.

Multifunctional species were split into several surrogate species, based on pre-specified priorities. For example, the difunctional molecule $\mathrm{CH}_{3} \mathrm{CH}\left(\mathrm{ONO}_{2}\right) \mathrm{COCH}_{3}$ is replaced by $\mathrm{CH}_{3} \mathrm{CH}\left(\mathrm{ONO}_{2}\right) \mathrm{CH}_{3}$ because priority is given to the nitrate function conservation, while the excess carbon is assigned to MEK, using an artificial stoichiometric coefficient of 0.25 to ensure carbon conservation. However, functional groups were not split for some multifunctional molecules whose reactivity depends strongly on the interaction between those functional groups. Thus, higher $\alpha$-dicarbonyls were replaced by methyl glyoxal or biacetyl (depending on whether they are internal or external carbonyls), and the unsaturated $\gamma$ dicarbonyls stemming from aromatic oxidation were retained explicitly.

A different treatment was applied to alcohols, which are produced in high numbers from the isomerization of long chain alkoxy radicals and the $\mathrm{RO}_{2}$ permutation reactions. Their reaction with $\mathrm{OH}$ leads to the formation of a carbonyl compound and the restitution of a radical species $\left(\mathrm{HO}_{2}\right)$. Therefore alcohol functional groups were directly replaced by carbonyl functional groups and an organic alcohol surrogate having zero carbon mass (noted OPEALC in Appendix A) which converts $\mathrm{OH}$ to $\mathrm{HO}_{2}$. The carbonyls were then assigned to surrogates as described in the preceding paragraphs.

As previously stated for the primary surrogates, the concentrations of surrogate secondary VOCs cannot be compared directly with their measured atmospheric concentrations, because they actually represent the sum of many different compounds. This limitation is not specific to our approach, but exists for all reduced chemical schemes using lumping or surrogate methods. Still, the sum of organic functionalities may remain meaningful (especially for reservoir species such as nitrates), as suggested by comparisons between the reduced and more complete reference schemes (Sect. 6). The number of species and reactions of the scheme after these reductions is presented Fig. 1.

\section{Results for the various scenarios}

Reduction methods were applied successively to the explicit scheme, except that the operators and grouping of primary species were first tested independently before being combined. The order of application of the reduction methods and the numbers of species and reactions after each reduction step are presented in Fig. 1. The reduced schemes were then tested by comparison with the reference scheme in a box model for the various conditions previously described.

For each scenario, a preliminary analysis using the reference scheme was first performed to characterize the dominant chemistry of the scenario and therefore to identify which aspects of the reduction methods would be tested by this scenario. For example, since VOCs react mainly with $\mathrm{OH}$, the reactivity of the air masses was estimated by computing for all scenarios the term $\sum k_{(\mathrm{OH}+\mathrm{VOC}) i} \times[\mathrm{VOC}]_{i}$. In the same way, the contribution of primary, secondary and $\mathrm{C}_{1}$ organic species to the total reactivity were determined. The branching ratios for the reactions of peroxy radicals were also quantified to identify the importance of using reductions by the operator method. The main results of this preliminary analysis are briefly mentioned hereafter for each scenario and the results of reduction are then presented.

\subsection{Polluted area (urban and regional scenarios)}

The urban and regional scenarios are characterized by intense emissions of ozone precursors. Hence, primary VOC was found to play the main role in the reactivity $(80 \%$ in the urban scenario and $40 \%$ to $80 \%$ in the regional scenario for summer and winter conditions respectively). Furthermore, in these scenarios, the organic peroxy radicals react mainly with NO, except for the regional summer conditions in which the $\mathrm{RO}_{2}+\mathrm{RO}_{2}$ and $\mathrm{RO}_{2}+\mathrm{HO}_{2}$ reactions reach up to about $20 \%$ during the day and $60 \%$ during the night (other nightime pathways being about $25 \%$ for reaction with $\mathrm{NO}$ and $15 \%$ with $\mathrm{NO}_{3}$ ).

Figure 6 shows the simulated diurnal profiles at different reduction levels for $\mathrm{O}_{3}, \mathrm{NO}_{\mathrm{x}}$ and $\mathrm{RO}_{\mathrm{x}}$ $\left(\mathrm{CH}_{3} \mathrm{O}_{2}+\mathrm{HO}_{2}+\mathrm{OH}+\mathrm{RO}_{2}\right)$. For the urban scenario (both summer and winter conditions) ozone and $\mathrm{NO}_{\mathrm{x}}$ concentrations are well reproduced for all reduction levels, with relative errors of $1.4 \%$ for $\mathrm{O}_{3}$ and less than $1 \%$ for $\mathrm{NO}_{\mathrm{x}}$ concentrations. The overall features of $\mathrm{RO}_{\mathrm{x}}$ concentrations are also well reproduced, however with an overestimation of about $10 \%$ during the night. For the regional scenarios, good overall agreement is found, but summertime $\mathrm{NO}_{\mathrm{x}}$ is overpredicted by up to $5 \%$ due to the use of operators. This bias is related to the relatively low NO concentrations (a few hundred ppt) allowing peroxy radical recombination which are treated only approximately in the operator scheme. For both summer and winter conditions, radical concentrations $\left(\mathrm{RO}_{\mathrm{x}}\right)$ show a slight overestimation during the day and underestimation during the night. The nighttime sources of radicals are the reactions of the VOC with $\mathrm{NO}_{3}$ and $\mathrm{O}_{3}$, and the deviation of radical concentrations is due to the aggregation of primary species. The daytime deviations of radical species are mainly due to the use of operators and, partly, to the aggregation of secondary species, which play a significant role in the organic reactivity with $\mathrm{OH}$ (10 to $30 \%)$.

These tests show that, in moderately to highly polluted conditions, chemistry is not very sensitive to the reductions. However, in these scenarios, the flushing time of the air in the box is shorter than the running time of the simulation. The simulated concentrations are therefore significantly influenced by boundary conditions. Impacts of the reduction 

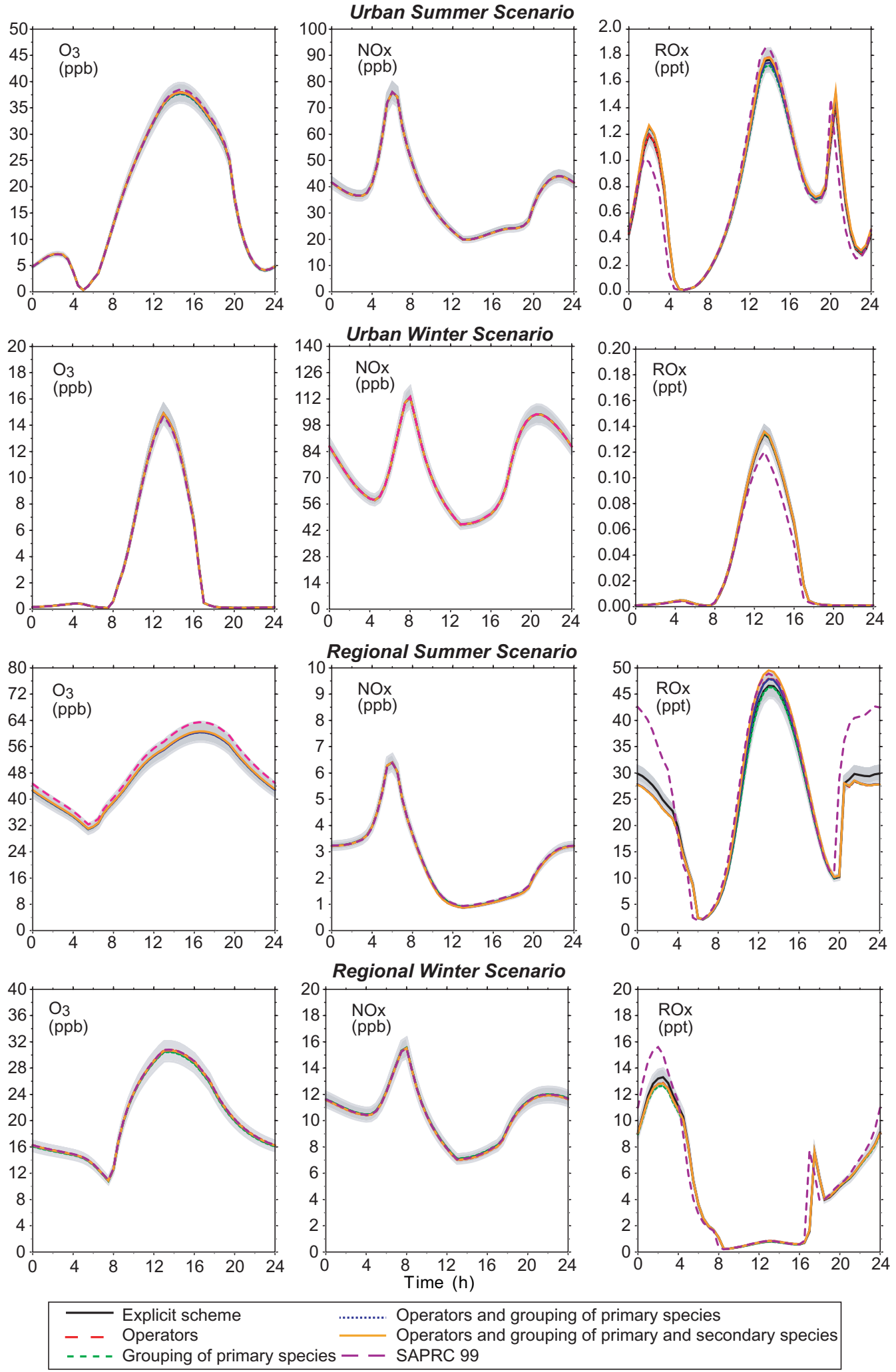

Fig. 6. Ozone, $\mathrm{NO}_{\mathrm{x}}$ and $\mathrm{RO}_{\mathrm{x}}\left(\mathrm{CH}_{3} \mathrm{O}_{2}+\mathrm{HO}_{2}+\mathrm{OH}+\mathrm{RO}_{2}\right)$ mixing ratios simulated with the reference explicit and the reduced schemes for the polluted scenarios. The pale gray zones represent a deviation of $5 \%$ around the explicit scheme results. The $24 \mathrm{~h}$ diurnal profiles are given for the fifth day. 

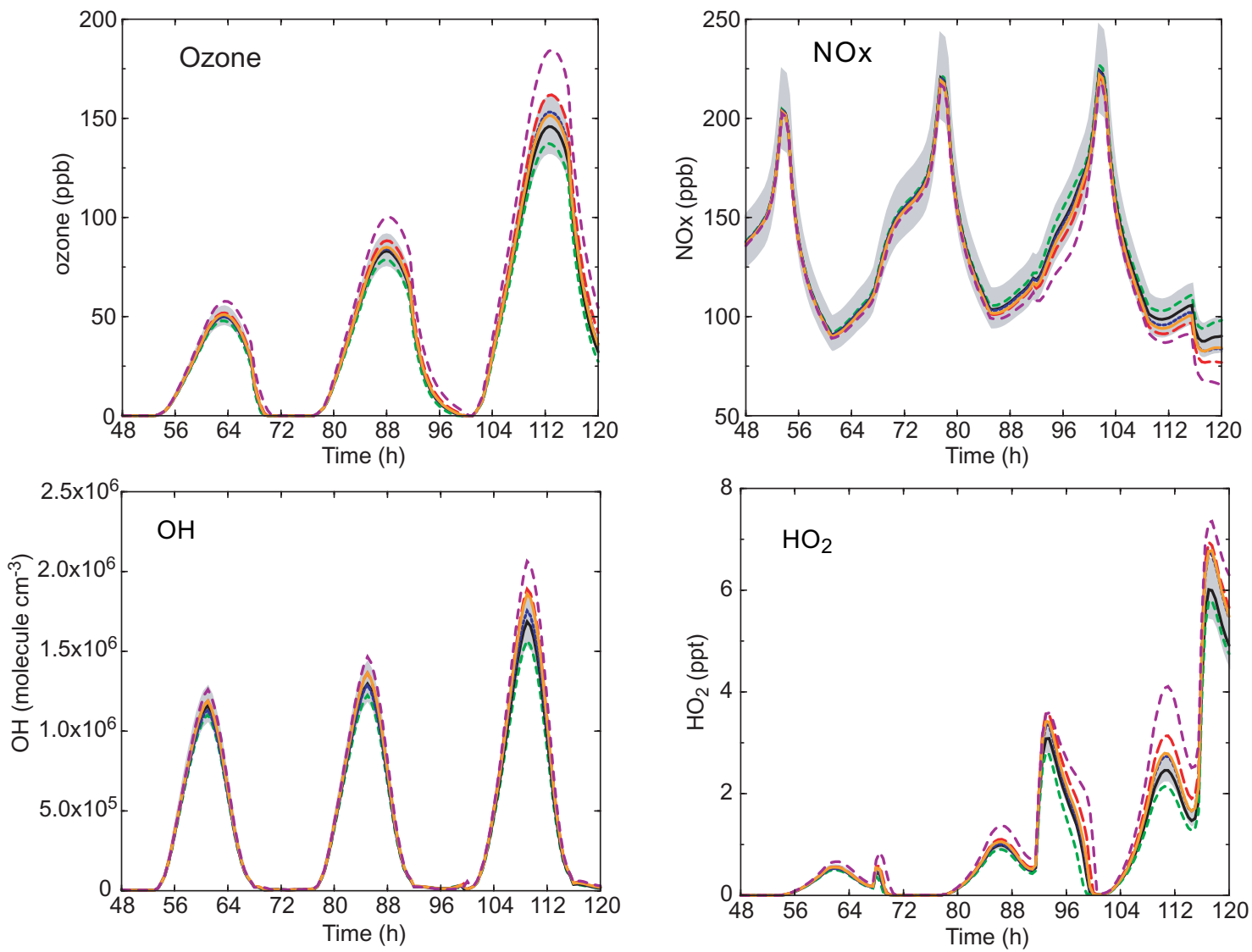

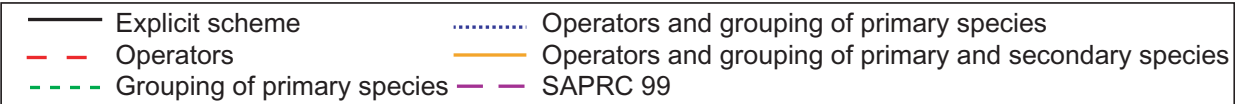

Fig. 7. Ozone, $\mathrm{NO}_{\mathrm{x}}$ and $\mathrm{HO}_{2}$ mixing ratios and $\mathrm{OH}$ concentrations simulated with the reference (explicit) and the reduced schemes for the urban summer scenario, without advection. The pale gray zones represent a deviation of $10 \%$ around the explicit scheme results.

are then attenuated, boundary conditions being not modified by them. In order to highlight the errors that may result from the reductions, a simulation in urban conditions was performed without any renewing of the air inside the box (i.e. no advection of air inside and outside the box is considered). This test leads to high ozone and $\mathrm{NO}_{\mathrm{x}}$ concentrations (150-250 ppb). Results are shown Fig. 7 for ozone, $\mathrm{NO}_{\mathrm{x}}, \mathrm{OH}$ and $\mathrm{HO}_{2}$. As the two first days do not show significant deviations, they are not shown on this picture. Deviations between the different schemes increase substantially in these conditions. Ozone production is decreased by aggregating the primary species ( $-5 \%$ and $-5.9 \%$ for the fourth and fifth days respectively) whereas it is increased by the use of operators (+6.4 and $+10.8 \%$ for the same peaks). Chemical schemes combining both hypotheses provide the best results $(2.4 \%$ and $3.7 \%$ for the last two peaks) due to error compensation. The $\mathrm{OH}$ concentration integrated over the whole last day is overestimated by $9 \%$ for the most reduced scheme. $\mathrm{NO}_{\mathrm{x}}$ profiles are also well represented although the concentrations di- verge slightly at the end of the simulation (6\% for the most reduced scheme). This bias is due to the overestimation of $\mathrm{OH}$ levels, as $\mathrm{NO}_{2}$ consumption is mostly controlled by the $\mathrm{OH}+\mathrm{NO}_{2}$ reaction. Finally, the use of operators leads to an overestimation of $\mathrm{HO}_{2}$ concentrations (up to $20 \%$ during the diurnal maximum). Overall, these comparisons show that even for very polluted scenarios (high $\mathrm{NO}_{\mathrm{x}}$ levels), concentrations computed with reduced schemes are close to those obtained with explicit scheme.

\subsection{Free relaxation of air masses in lower tropospheric con- ditions}

These scenarios, with neither emission nor advection, are characterized by rapid loss of $\mathrm{NO}_{\mathrm{x}}$. After two days, $\mathrm{NO}_{\mathrm{x}}$ levels are relatively low: a few tens ppt for summer conditions, and less than $3 \mathrm{ppb}$ for winter conditions. These tests are then highly sensitive to the competition between $\mathrm{RO}_{2}+\mathrm{NO}$ reactions and $\mathrm{RO}_{2}+\mathrm{HO}_{2}$ (or $\mathrm{R}^{\prime} \mathrm{O}_{2}$ ) reactions, and therefore to the reduction assumptions involving operators. Furthermore, 
secondary VOC chemistry is a major contributor to the total $\mathrm{OH}$ reactivity in these scenarios (respectively $30 \%$ and $60 \%$ for summer and winter cases). These tests thus remain highly sensitive to the reduction of secondary species. We point out that in these scenarios, $\mathrm{C}_{1}$ chemistry also plays a major role in $\mathrm{OH}$ reactivity, i.e. growing from $30 \%$ to $60 \%$ during the 5 -days summer simulation but remaining below $20 \%$ in the winter scenario.

Results are presented for ozone, $\mathrm{NO}_{\mathrm{x}}$ and $\mathrm{RO}_{\mathrm{x}}$ in Fig. 8. For summer conditions, net ozone destruction occurs after the second day. During the first day, it was found that the $\mathrm{RO}_{2}+\mathrm{NO}$ reactions contribute on average to about $50 \%$ of organic peroxy removal and that the $\mathrm{RO}_{2}+\mathrm{HO}_{2}$ and $\mathrm{RO}_{2}+\mathrm{RO}_{2}$ reactions account for $40 \%$ and $10 \%$, respectively. The second to the fifth days are dominated by the $\mathrm{RO}_{2}+\mathrm{HO}_{2}$ and $\mathrm{RO}_{2}+\mathrm{RO}_{2}$ reactions (respectively $50 \%$ and $20 \%$ ) and only about $30 \%$ of the removal of organic peroxy is due to the reaction with NO. For this scenario, concentrations of the inorganic species are relatively well reproduced although accuracy of the reduced schemes decreases slightly with time. However, even after five days, the relative error in ozone concentrations is less than $5 \%$ in this scenario. This error is mainly due to the operator reduction (see Fig. 8). The use of operators and the aggregation of secondary species lead to a decrease of $\mathrm{NO}_{\mathrm{x}}$ concentrations, with a maximum bias at the end of the simulation of $8 \mathrm{ppt}(20 \%)$ with the most reduced scheme. Biases in the daytime concentrations of $\mathrm{RO}_{\mathrm{x}}$ are less than $5 \%$ but concentrations are underestimated by $10 \%$ during the night.

For winter conditions (see Fig. 8), ozone concentrations are affected only slightly by the reductions (bias $<3 \%$ ). Nevertheless, $\mathrm{NO}_{\mathrm{x}}$ concentrations are underestimated by up to $0.26 \mathrm{ppb}$ (i.e. a $33 \%$ bias) due to the use of operators. Radical species are underestimated somewhat (up to $10 \%$ ) by the aggregation of the primary species. Operators lead to an overestimation of radicals (up to $30 \%$ during the night but less than $10 \%$ for diurnal values).

These tests show that for low $\mathrm{NO}_{\mathrm{x}}$ conditions, ozone concentrations are well captured by the reduced chemical schemes. Nevertheless $\mathrm{NO}_{\mathrm{x}}$ concentrations are biased toward a systematic underestimation due to the use of operators.

5.3 Free relaxation of air masses in free tropospheric conditions

The role played by one-carbon species in this scenario does not exceed $25 \%$ after 5 days. The impact of the reductions can thus be examined without being masked by the $\mathrm{C}_{1}$ chemistry. Results for this scenario are presented Fig. 9. The ozone profile is affected only slightly by the reductions. On the other hand, $\mathrm{NO}_{\mathrm{x}}$ is underestimated significantly by the reduced schemes (about $40 \%$ after $24 \mathrm{~h}$ ). It is nevertheless important to notice that this bias, which results from the use of operators, does not increase with time after $30 \mathrm{~h}$. Further- more this error is less than that of SAPRC which increases throughout the simulation (see Fig. 9).

\section{Summary of biases due to the reduction methods}

Three main methods were automated to decrease the size of chemical schemes describing the VOC oxidation in the troposphere: (1) The first one is the grouping of primary species into surrogate species. It does not lead to a significant bias for the key inorganic species (i.e. $\mathrm{O}_{3}, \mathrm{OH}, \mathrm{NO}_{\mathrm{x}}$ ). This reduction is then suitable to a wide range of environmental conditions. (2) The second method is the use of chemical operators to represent the contribution of organic peroxy radicals to the $\mathrm{NO}_{\mathrm{x}}$ and $\mathrm{RO}_{\mathrm{x}}$ budgets. This reduction induces no significant bias for high $\mathrm{NO}_{\mathrm{x}}$ conditions. However, $\mathrm{NO}_{\mathrm{x}}$ is systematically underestimated for low $\mathrm{NO}_{\mathrm{x}}$ conditions because of the incomplete representation of the competition between the reaction of peroxy radicals with NO and with other peroxy radicals. This bias can reach $30 \%$ after five days for air masses having no injection of primary species. A bias in radical species is also observed after five days for wintertime free tropospheric conditions. (3) The last reduction is the replacement of secondary species by surrogate species. This reduction does not influence concentrations for polluted conditions which are continuously subjected to fresh VOC emissions. Errors due to this reduction are then limited to situations not subjected to large VOC emission. The impact on $\mathrm{RO}_{\mathrm{x}}$ and $\mathrm{NO}_{\mathrm{x}}$ is small for the first three days but reaches ca. $10 \%$ after five days. For winter conditions, the grouping of secondary species induces an overestimation of $\mathrm{RO}_{\mathrm{x}}$, which compensates the underestimation due to operators.

After these reductions, the number of species in the scheme is sufficiently low to be implemented in a 3-Dchemistry transport model. The box model simulations showed that ozone concentrations are simulated well by the reduced scheme, with error (relative to the reference scheme) systematically less than 5\% which, for the simulated conditions, corresponds to a maximum error of $1.5 \mathrm{ppb}$.

For every situations considered here, the reduced scheme reproduced the $\mathrm{OH}$ integral with less than $4 \%$ error, except for urban scenario without advection (10\%), but these conditions are hardly realistic.

General features of $\mathrm{NO}_{\mathrm{x}}$ are well reproduced for urban to continental situations. However, a problem due to an overestimation of the $\mathrm{NO}_{\mathrm{x}}$ storage in organic compounds is highlighted for long range transport of air masses. Nevertheless, these scenarios may be rather unrealistic because they consider air masses without any incorporation of new precursors during 5 days. Errors found here are therefore likely to be upper limits.

Acetone is a ubiquitous compound in the troposphere, due to its low reactivity. In the urban and regional scenarios, the exportable amount of acetone (taken here as the integral of acetone concentrations over the fifth day) is underestimated 
Relaxation of an old continental air mass in summer conditions
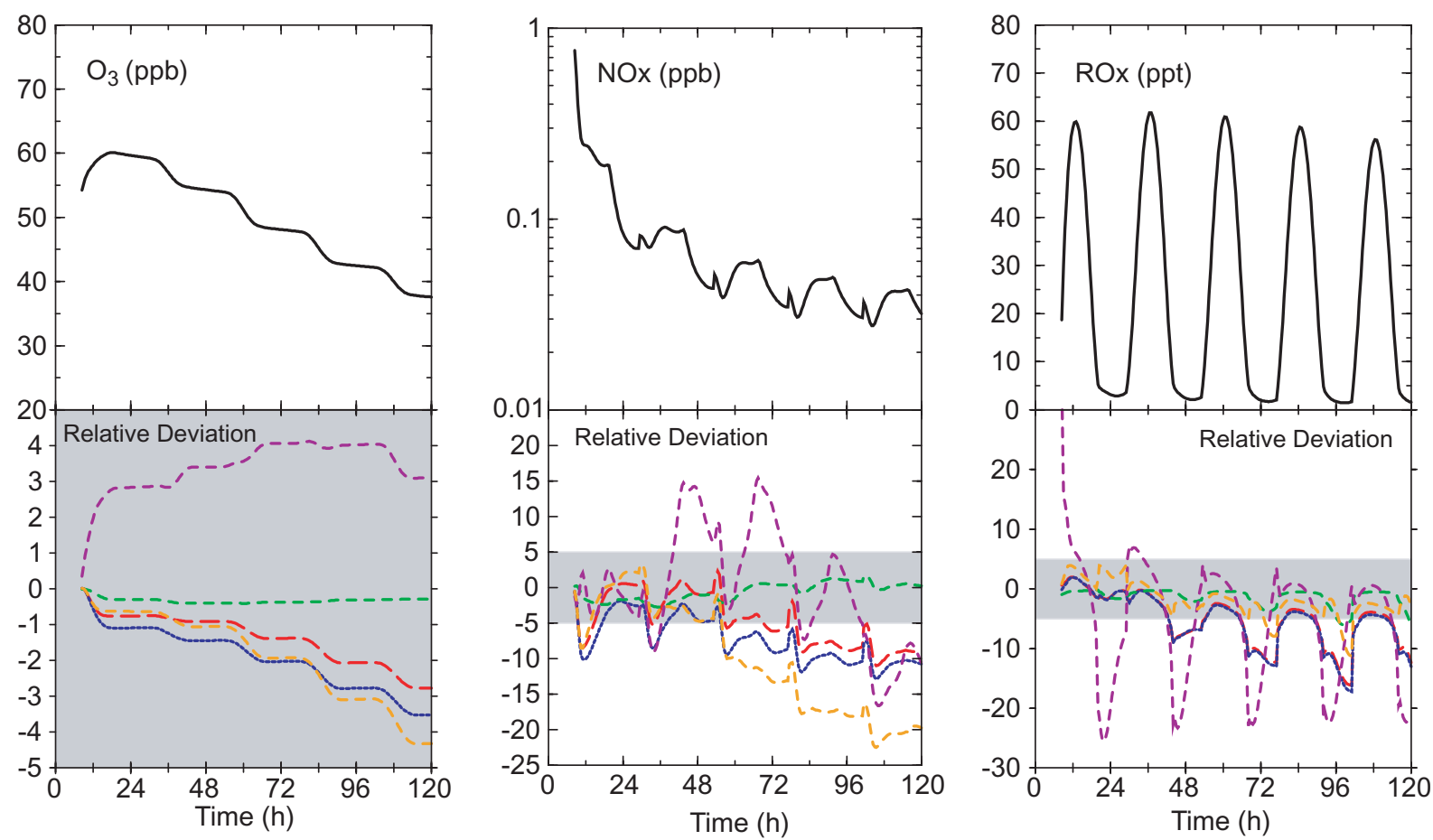

Relaxation of an old continental air mass in winter conditions
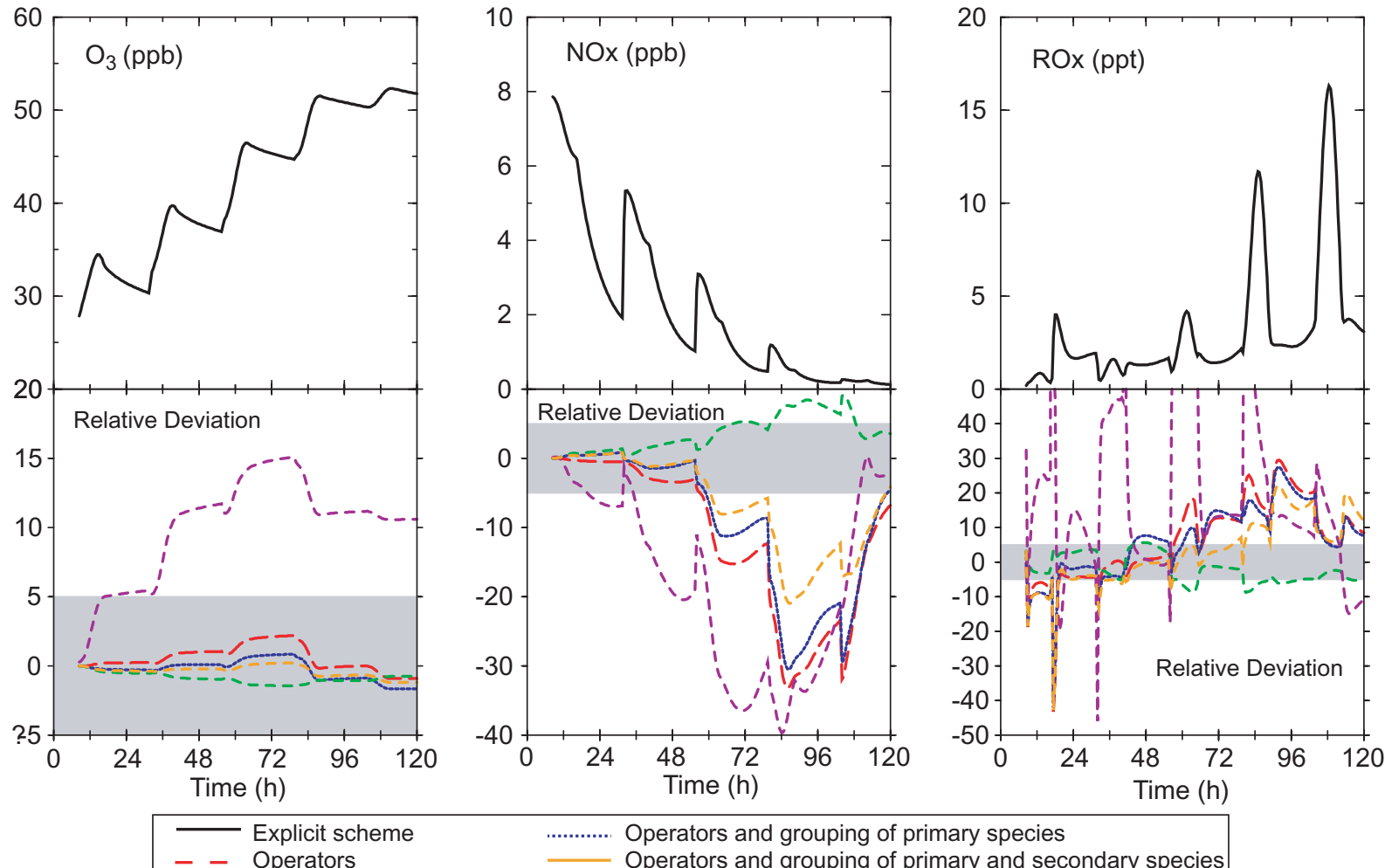

- Operators

Operators and grouping of primary species

Operators and grouping of primary and secondary species

- - - - Grouping of primary species - - SAPRC 99

Fig. 8. Ozone, $\mathrm{NO}_{\mathrm{x}}$ and $\mathrm{RO}_{\mathrm{x}}\left(\mathrm{CH}_{3} \mathrm{O}_{2}+\mathrm{HO}_{2}+\mathrm{OH}+\mathrm{RO}_{2}\right)$ mixing ratios simulated with the reference explicit scheme for the relaxation scenarios without emission, and relative deviation of the reduced scheme with respect to the reference scheme. The pale gray zones represent a deviation of $5 \%$ around the reference scheme. 


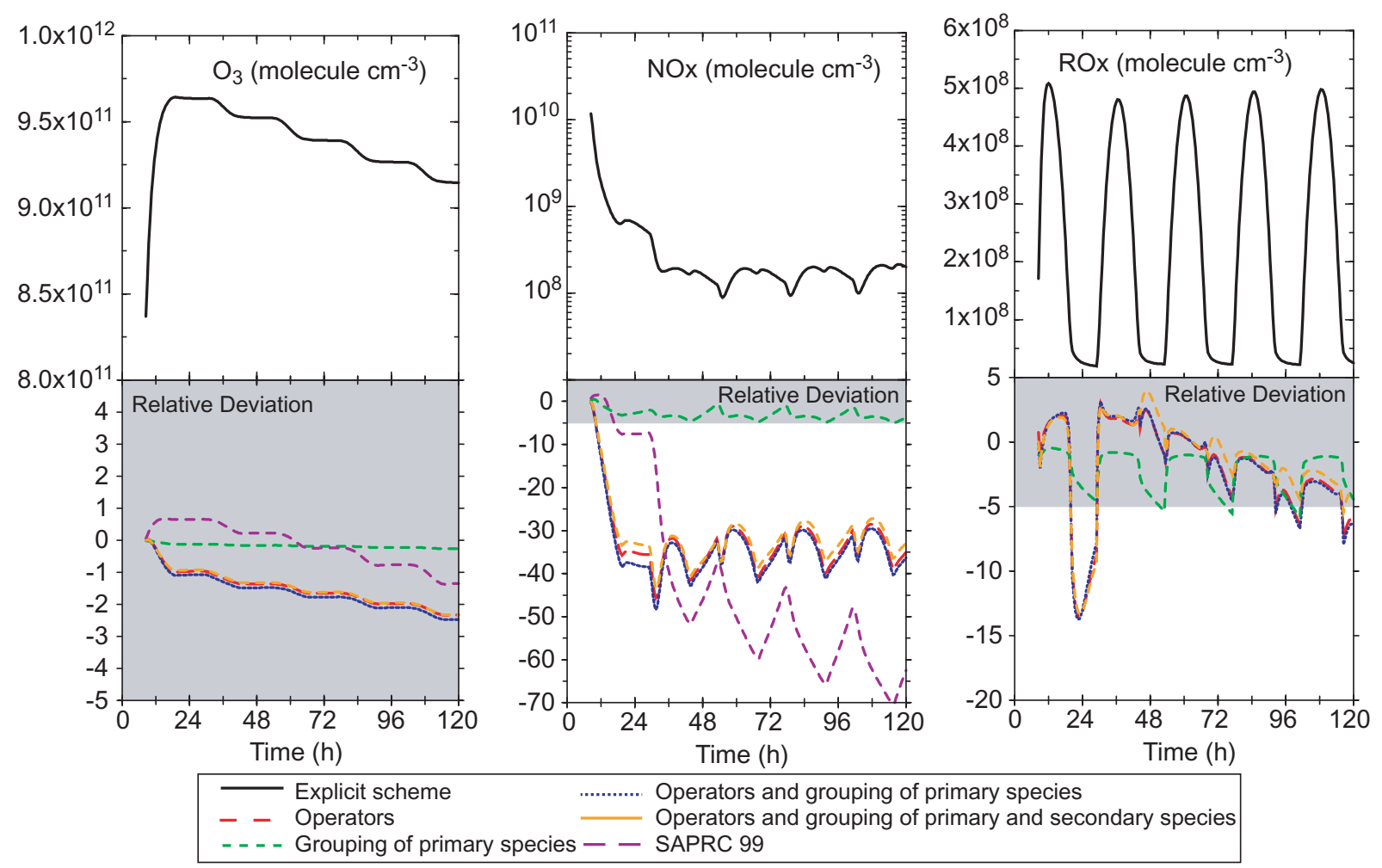

Fig. 9. Ozone, $\mathrm{NO}_{\mathrm{x}}$ et $\mathrm{RO}_{\mathrm{x}}\left(\mathrm{CH}_{3} \mathrm{O}_{2}+\mathrm{HO}_{2}+\mathrm{OH}+\mathrm{RO}_{2}\right)$ concentrations simulated with the reference scheme for the relaxation scenarios at $5 \mathrm{~km}$, and relative deviation of the reduced scheme with respect to that reference. The pale gray zones represent a deviation of $5 \%$ around the explicit scheme.

by 0.3 to $11 \%$ with respect to the reference scheme. For the free relaxation air masses, acetone concentrations increase during the whole simulation. In these scenarios, acetone production in the most reduced scheme is underestimated by 20 to $30 \%$.

$\mathrm{H}_{2} \mathrm{O}_{2}$ is one of the main oxidants in the aqueous phase. The good simulation of its concentrations is directly linked to the good representation of the $\mathrm{HO}_{2}$ chemistry. $\mathrm{H}_{2} \mathrm{O}_{2}$ concentration is estimated with less than $10 \%$ of error.

Nitric acid is involved in the aerosol production and is scavenged by water droplets resulting in acidification of clouds and fogs. A good simulation of its concentration shows evidence of a good representation of the chemistry of $\mathrm{OH}$ and $\mathrm{NO}_{2}$. Biases on this species never exceed $6 \%$.

Regarding the organic functions (aldehydes, ketones, PAN, nitrates, alcohols, carboxylic acids), a fairly good agreement is found between explicit and reduced chemical schemes with a difference of less than $10 \%$ for highly polluted scenarios. For moderately polluted scenarios, organic functionalities are reproduced with a bias of less than $10 \%$ except nitrates in summer (up to $15 \%$ deviation), alcohols in winter (up to $50 \%$ deviation), ketones in winter (up to $25 \%$ deviation) and carboxylic acids in winter (up to $20 \%$ deviation). Note that the fairly good results in simulating PAN and nitrates are of particular interest here since these species are key reservoir compounds transporting $\mathrm{NO}_{\mathrm{x}}$ from polluted to remote areas. For the scenarios representing the free relaxation of air masses, the differences between the explicit and the reduced scheme never exceed 55\% (being systematically lesser than $30 \%$ for winter and free tropospheric conditions) for the organic functions.

In summary, all the tests performed so far show a fairly good agreement between the reduced chemical scheme and the reference scheme to reproduce the gaseous chemistry of the system $\mathrm{O}_{3} / \mathrm{NO}_{\mathrm{x}} / \mathrm{VOCs}$.

\section{Conclusions}

A reference scheme was developed with the help of an expert system to generate a chemical scheme as explicitly as currently practical. This reference scheme describes the oxidation of 70 representative primary species, with about 350000 species and 2 million reactions. Simulations carried out for typical continental conditions show that the simulated concentrations agree well with those simulated using SAPRC99.

This reference scheme was used as a benchmark to evaluate some reduction methods typically used in the development of reduced schemes. Three main methods were tested to reduce the size of an explicit chemical scheme: (i) 
chemical operators to represent the contribution of organic peroxy radicals to the $\mathrm{NO}_{\mathrm{x}}$ and $\mathrm{NO}_{\mathrm{x}}$ budget (ii) grouping of primary species into surrogate species (iii) grouping of secondary products into surrogate species. These reduction methods can be automated to allow fast writing and facilitate modifications with future updates.

The number of species in the final reduced scheme is 147 , i.e. low enough for 3-D modeling purposes using CTMs. The reduced scheme showed fairly good accuracy in modeling the chemistry for conditions of continuous precursors emissions (urban or regional areas). For conditions with lower $\mathrm{NO}_{\mathrm{x}}$ concentrations, a systematic bias was noted during the transition from the regime where $\mathrm{RO}_{2}$ radicals react almost totally with $\mathrm{NO}$ to that where a significant concurrence of the $\mathrm{RO}_{2}+\mathrm{HO}_{2}$ and $\mathrm{RO}_{2}+\mathrm{RO}_{2}$ reactions takes place. This bias is due to an overestimation of the storage of nitrogen in organic compounds. The error (maximum of $30-40 \%$ for the tested conditions) first emerges during the transition between the two peroxy radicals regimes but then remains constant. Other key species involved in tropospheric chemistry (radicals and ozone) are very well simulated in the various conditions studied (respectively $\pm 10 \%$ and $\pm 4 \%$ ). This chemical scheme is therefore able to properly simulate the $\mathrm{VOC} / \mathrm{NO}_{\mathrm{x}} / \mathrm{HO}_{\mathrm{x}} / \mathrm{O}_{3}$ chemistry in various tropospheric situations, from polluted to remote conditions.

Acknowledgements. We are thankful to W. P. L. Carter for providing downloadable version of the SAPRC mechanism. NCAR is sponsored by the National Science Foundation.

Edited by: A. Volz-Thomas

\section{References}

Atkinson, R., Baulch, D. L., Cox, R., Hampson, R., Kerr, J., and Rossi, M.: Evaluated kinetics and photochemical data for atmospheric chemistry, Organic species: Supplement VII, J. Phys. Chem. Ref. Data, 28, 191-392, 1999.

Aumont, B., Jaecker-Voirol, A., Martin, B., and Toupance, G.: Tests of some reduction hypothesis in photochemical mechanisms: application to air quality modeling in the Paris area, Atmos. Environ., 30, 2061-2077, 1996.

Aumont, B., Chervier, F., and Laval, S.: Contribution of HONO sources to the $\mathrm{NO}_{\mathrm{x}} / \mathrm{HO}_{\mathrm{x}} / \mathrm{O} 3$ chemistry in the polluted boundary layer, Atmos. Environ., 37, 487-498, 2003.

Aumont, B., Szopa, S., and Madronich, S.: Modelling the evolution of organic carbon during its gas-phase tropospheric oxidation: development of an explicit model based on a self generating approach, Atmos. Chem. Phys., 5, 2497-2517, 2005,

\section{SRef-ID: 1680-7324/acp/2005-5-2497.}

Bey, I., Aumont, B., and Toupance, G.: A modeling study of the nighttime radical chemistry in the lower continental troposphere. 1. Development of a detailed chemical mechanism including nighttime chemistry, J. Geophys. Res., 106, 9959-9990, 2001.

Calvert, J. G. and Madronich, S.: Theoretical study of the initial products of the atmospheric oxidation of hydrocarbons, J. Geophys. Res., 92, 2211-2220, 1987.
Carter, W.: A Detailed Mechanism for the Gas-Phase Atmospheric Reactions of Organic Compounds, Atmos. Environ., 24A, 481518, 1990.

Carter, W. P. L.: Documentation of the SAPRC-99 chemical mechanism for the VOC reactivity assessment, Final Report to the California Air Resources Board under Contracts 92-329 and 95-308, Center of Environmental Research and Technology, Riverside, 2000. http://pah.cert.ucr.edu/ carter/SAPRC99.htm.

Derwent, R. and Jenkin, M.: Hydrocarbons and long-range transport of ozone and PAN across Europe, Atmos. Environ., 25A, 1661-1678, 1991.

Fiore, A., Jacob, D., Bey, I., Yantosca, R., Field, B., and Fusco, A.: Background ozone over the United States in summer : Origin, trend and contributions to pollution episodes, J. Geophys. Res., 107, 4275, doi:10.1029/2001JD000982, 2002.

Gery, M., Whitten, G. Z., and Killus, J., and Dodge, M.: A photochemical kinetics mechanism for urban and regional computer modeling., J. Geophys. Res., 94, 12 925-12 956, 1989.

Hough, A.: The production of photochemical pollution in southern England and the effect on vehicle exhaust emission control strategies, AERE Report R-12069, Harwell Laboratory, 1986.

Jaegle, L., Jacob, D., Brune, W., and Wennberg, P.: Chemistry of $\mathrm{HO}_{\mathrm{x}}$ radicals in the upper troposphere, Atmos. Environ., 35, 469-489, 2001.

Jenkin, M., Saunders, S., Derwent, R., and Pilling, M.: Development of a reduced speciated VOC degradation mechanism for use in ozone models, Atmos. Environ., 30, 4725-4734, 2002

Jenkin, M. E., Saunders, S. M., Wagner, V., and Pilling, M. J.: Protocol for the development of the Master Chemical Mechanism, MCM v3 (Part B): tropospheric degradation of aromatic volatile organic compounds, Atmos. Chem. Phys., 3, 181-193, 2003, SRef-ID: 1680-7324/acp/2003-3-181.

Laval-Szopa, S.: Développement d'une chaine automatique d'écriture de schémas chimiques explicites et réduits adaptés à l'étude de la pollution photooxydante, $\mathrm{PhD}$ thesis, University of Paris XII, December 2003, available at http://tel.ccsd.cnrs.fr/ documents/archives0/00/00/65/99/index.html.

Lesclaux, R.: Combination of peroxyl radicals in the gas phase, in: Peroxyl Radicals, edited by: Alfassi, Z. B., 81-112, John Wiley, New York, 1997.

Li, Q., Jacob, D., Bey, I., Palmer, P., Duncan, B., Field, B., Martin, R., Fiore, A., Yantosca, R., Parrish, D., Simmonds, P., and Oltmans, S.: Transatlantic transport of pollution and its effects on surface ozone in Europe and North America, J. Geophys. Res., 107, 4166, doi:10.1029/2001JD001422, 2002.

Längmann, B. and Bauer, S.: On the importance of reliable background concentrations of ozone for regional scale photochemical modelling, J. Atmos. Chem., 42, 71-90, 2002.

Madronich, S. and Calvert, J. G.: Permutation reactions of organic peroxy radicals in the troposphere, J. Geophys. Res., 95, 56975715, 1990.

Madronich, S. and Flocke, S.: The role of solar radiation in atmospheic chemistry, in: Handbook of environmental chemistry, edited by: Boule, P., 1-26, Springer, New York, 1998.

Middleton, P., Stockwell, W., and Carter, W.: Aggregation and analysis of volatile organic compound emissions for regional modeling, Atmos. Environ., 24, 1107-1133, 1990.

Moxim, W., Levy, I. H., and Kasibhatla, P.: Simulated global tropospheric PAN: Its transport and impact on $\mathrm{NO}_{\mathrm{x}}$, J. Geophys. Res., 
101, 12 621-12 638, 1996.

Müller, J. and Brasseur, G.: Sources of upper tropospheric $\mathrm{HO}_{\mathrm{x}}$ : A three dimensional study, J. Geophys. Res., 104, 1705-1715, 1999.

Poppe, D., Aumont, B., Ervens, B., Geiger, H., Herrmann, H., Rth, E., Seidl, W., Stockwell, W., Vogel, B., Wagner, S., and Weise, D.: Scenarios for modeling multiphase tropospheric chemistry, J. Atmos. Chem., 40, 77-86, 2001.

Prather, M. and Jacob, D.: A persistent imbalance in $\mathrm{HO}_{\mathrm{x}}$ and $\mathrm{NO}_{\mathrm{x}}$ photochemistry of the upper troposphere driven by deep tropical convection, Geophys. Res. Lett., 24, 3189-3192, 1997.

Programme, W. C. R.: A preliminary cloudness standard atmosphere for radiation computation, WMO/TD 24, International Association for Meteorology and Atmospheric Physics - Radiation Commission, 1986.

Sander, S. P., Friedl, R. R., De More, W. B., Golden, D. M., Kurylo, M. J., Hampson, R. F., Huie, R. E., Moortgat, G., Ravishankara, A. R., Kolb, C. E., and Molina, L. T.: Chemical kinetics and photochemical data for use in stratospheric modeling, Jet Propulsion Laboratory, Pasadena, California, 2000.
Sillman, S., Logan, J., and Wosfy, S.: The sensitivity of ozone to nitrogen oxides and hydrocarbons in regional ozone episodes, J. Geophys. Res., 95, 1837-1851, 1990.

Simpson, D., Guenther, A., Hewitt, C., and Steinbrecher, R.: Biogenic emissions in Europe, 1. Estimates and uncertainties, J. Geophys. Res., 100, 22 875-23 373, 1995.

Stockwell, W., Kirchner, F., Kuhn, F., and Seefeld, S.: A new mechanism for regional atmospheric chemistry modeling, J. Geophys. Res., 102, 25 847-25 879, 1997.

Wennberg, P., Hanisco, T., Jaegle, L., Jacob, D., Hintsa, E., Lanzendorf, E., Anderson, J., Gao, R., Keim, E., Donnelly, S., Del Negro, L., Fahey, D., McKeen, S., Salawitch, R., Webster, C., May, R., Herman, R., Proffitt, M., Margitan, J., Atlas, E., Schauffler, S., Flocke, F., McElroy, C., and Bui, T.: Hydrogen radicals, Nitrogen radicals, and the Production of $\mathrm{O} 3$ in the Upper Troposphere, Science, 279, 49-53, 1998.

Wesely, M. L.: Parameterization of surface resistances to gaseous dry deposition in regional-scale numerical models, Atmos. Environ., 23, 1293-1304, 1989. 